\title{
Multi-Scale Measurement of Regional Inequality in Mainland China during 2005-2010 Using DMSP/OLS Night Light Imagery and Population Density Grid Data
}

\section{Huimin Xu ${ }^{1, *}$, Hutao Yang ${ }^{1}, \mathrm{Xi} \mathrm{Li}^{2,3,4, *}$, Huiran Jin ${ }^{4}$ and Deren $\mathrm{Li}^{2,3}$}

1 School of Economics, Zhongnan University of Economics and Law, Wuhan 430073, China; E-Mail: yanghutao@znufe.edu.cn

2 State Key Laboratory of Information Engineering in Surveying, Mapping and Remote Sensing, Wuhan University, Wuhan 430079, China; E-Mail: drli@whu.edu.cn

3 Collaborative Innovation Centre of Geospatial Technology, Wuhan 430079, China

4 Department of Geographical Sciences, University of Maryland, College Park, 20742 MD, USA; E-Mails: hrjin@umd.edu

* Authors to whom correspondence should be addressed;

E-Mails: xuhuimin1985_2008@163.com (H.X.); li_rs@163.com (X.L.) or lixi@whu.edu.cn (X.L.); Tel.: +86-27-8838-6464 (H.X.); +86-27-6877-8989 (X.L.); Fax: +86-27-8838-6239 (H.X.), $+86-27-6877-8989$ (X.L.)

Academic Editor: Eric Vaz

Received: 1 August 2015 / Accepted: 22 September 2015 / Published: 30 September 2015

\begin{abstract}
This study used the Night Light Development Index (NLDI) to measure the regional inequality of public services in Mainland China at multiple scales. The NLDI was extracted based on a Gini Coefficient approach to measure the spatial differences of population distribution and night light distribution. Population data were derived from the dataset of China's population density grid, and night light data were acquired from satellite imagery. In the multi-scale analysis, we calculated the NLDI for China as a whole, eight economic regions, 31 provincial regions, and 354 prefectural cities for the two years of 2005 and 2010. The results indicate that Southwest China and Northwest China are the regions with the most unequal public services, with NLDI values of 0.7116 and 0.7251 for 2005 , respectively, and 0.6678 and 0.6304 for 2010, respectively. In contrast, Northern Coastal China had the lowest NLDI values of 0.4775 and 0.4312 for 2005 and 2010, respectively, indicating that this region had the most equal public services. Also, the regional inequality of Mainland China in terms of NLDI has been reduced from 0.6161 to 0.5743 during 2005-2010.
\end{abstract}


The same pattern was observed from the provincial and prefectural analysis, suggesting that public services in Mainland China became more equal within the five-year period. A regression analysis indicated that provincial and prefectural regions with more public services per capita and higher population density had more equal public services.

Keywords: regional inequality; China; Lorenz Curve; night light; remote sensing

\section{Introduction}

China has experienced fast economic growth and urbanization since the end of the 1970s when the Reform and Opening policy was officially implemented. Although China's economy is growing rapidly, its uneven spatial pattern is evident. In China, strong contrasts exist between East and West, rural and urban regions, and even between different districts of the same city. Unequal regional development may cause social instability that hinders sustainable development [1,2]. Therefore, it is important to measure the regional inequality of China. Scholars attempted to measure this inequality with socioeconomic indicators such as Gross Domestic Product (GDP), GDP per capita, consumption, and investment [3-8]. A number of studies revealed that China's regional inequality had increased since the 1990s and began to decline after $2004[9,10]$. However, a new study found that much of the apparent increase in regional inequality and the reversal since 2005 is a statistical artifact due to using the registered population rather than the resident population [11].

Recently, researchers have realized that public services are important for sustainable development [12-15], and studies have consequently been carried out measuring regional inequality of public services such as education and health care in China [16-19]. Nearly all the previous studies used regionally aggregated indicators to measure the regional inequality. For example, provincial data were used to measure the regional inequality of China as a whole $[10,20]$, and prefectural or county data were used to measure the intra-provincial inequality [21,22]. This strategy does not account for the intra-regional inequality of the basic unit (e.g. prefectural cities), and therefore the inequality of these units was unknown. It is difficult to get disaggregated data for these basic units, especially at the prefectural scales, thus the intra-regional inequality is unknown.

In contrast to daytime remote sensing which is widely applied in land cover mapping [23-28], climate change analysis [29,30], and disaster management [31], night light remote sensing is an emerging technique that can potentially provide spatially continuous socioeconomic indicators because human activities are strongly correlated to night light [32,33]. Night light remote sensing has been widely used in many fields including socioeconomic parameter estimation [34-36], urbanization evaluation [37,38], fishing boat mapping [39], land cover mapping [40-43], and humanitarian disaster evaluation [44-46]. This technique provides an opportunity to map spatial distribution of GDP [47,48], energy consumption [49,50], and public services [51,52]. For China studies, the night light remote sensing has played an important role for evaluating the urbanization. As brightness of the land surface at night can help to discriminate urban areas from non-urban areas, extracting the urban extent by using a threshold applied in night time imagery has proved effective [38,53]. Therefore, multi-temporal night light images have been widely used to study China's rapid urbanization process. 
Based on this approach, Gibson and his colleagues found that the annual expansion rate of China's lit area in 287 prefectural cities during 1993-2012 is 8\%, which is higher than 5\% from official statistical yearbooks [37]. Yi and his colleagues proposed an Urban Light Index (ULI) to evaluate the urbanization process in 34 prefectural cities in Northeast China. They found that the ULI has increased during 1992-2010, and the urbanization is most significant during 2004-2010 [54]. Huang and his colleagues made use of night light images to evaluate city size and rank in China during 1992-2008, they found that the distribution of city sizes became more even during the period and the greatest change in city size distribution occurred during 2000-2003 [42]. Tan investigated the spatial pattern of China's urbanization during 1992-2010 using night light images. He found that the urban areas expanded much more quickly in the 2000s than the 1990s, and Eastern China had the most rapid urban growth in 1990s, while Middle China had the highest rate in the 2000s [55].

Since night light is an indicator of a number of socioeconomic parameters, the spatial disparity of night light has the potential to reflect the spatial disparity of development. A night light development index (NLDI) has been proposed to quantify the difference between population distribution and wealth distribution, the results of which are used to infer regional inequality [56]. The NLDI has been used to measure the inequality at national, sub-national, and gridded scales. One major advantage of NLDI is that the spatial inequality can be calculated at fine spatial scales. For example, Zhou and his colleagues used aggregated night light and population census data to measure the intra-regional inequality of China's 30 provinces for 2010 [57], and Liu and his colleagues utilized night light images to measure the development disparity of different ethnic groups in China during 2000-2013 [58]. In this study, night light is viewed as an indicator of public services rather than GDP. This is because: (1) the major component of night light is public lighting [59], which can reflect regional public services [51,52], and regions with poor lighting can be viewed as regions with poor public services; (2) although night light is strongly correlated with GDP at large scales such as administrative regions and coarse spatial resolution grid, the relationship at finer scales remains unknown; and (3) GDP in agricultural sectors is poorly related to night light $[33,60]$, as rural areas in developing countries are typically totally dark at night. For these reasons, night light is a good proxy for public services rather than GDP, and thus can help to evaluate public services with regard to their regional inequality. The purpose of this study was to measure the regional inequality of public services inside multi-scale regions and their changes during 2005-2010, using spatially continuous night light and population density grid data.

\section{Study Area and Data}

\subsection{Study Area and Original Data}

In this study, we make analysis at four scales, China as a whole, economic regions, provinces, and prefectural cities. China comprises 34 provincial regions, including 31 provinces in Mainland China, as well as Hongkong, Macau, and Taiwan. This study only focused on the 31 provincial regions in Mainland China. Hongkong, Macau, and Taiwan were excluded due to the lack of population density grid data. In China, provinces are the first-level administrative regions, and prefectural cities are the second level. All prefectural regions are included in this study. In China, counties are generally under governance of prefectural cities, but there are some counties that do not belong to any prefectural cities, 
which are called provincial counties. Therefore, all provincial counties (or the regions at the same level) are viewed as prefectural cities, which compose China's administrative regions at the second level. Four cities of Beijing, Tianjin, Shanghai, and Chongqing, directly under governance of the central government, are viewed as prefectural cities in the prefectural analysis. In total, 355 cities and counties were defined as prefectural cities. However, Ge'ermu City in Qinghai Province with no population density grid data available was excluded from this study. Thus, a total of 354 prefectural cities were used for the analysis.

Eight economic regions have been defined by China's Development Research Center of the State Council [61], and used in existing studies [38]. Table 1 lists the eight economic regions with their provincial members, and Table 2 lists the number of prefectural cities in different provinces. Figure 1 shows the map of the provincial and economic regions, and Figure 2 shows the map of the prefectural cities in China.

Table 1. Eight economic regions and their provincial members.

\begin{tabular}{cc}
\hline Economic Region & Provinces \\
\hline Northeast China (NEC) & Liaoning, Jilin and Heilongjiang \\
Northern Coastal China (NCC) & Beijing, Tianjin, Hebei and Shandong \\
Southern Coastal China (SCC) & Fujian, Guangdong, and Hainan, Taiwan, Hong Kong and Macao \\
Eastern Coastal China (ECC) & Shanghai, Jiangsu and Zhejiang \\
Middle Reaches of the Yellow River (MRYLR) & Shaanxi, Shanxi, Henan and Inner Mongolia \\
Middle Reaches of the Yangtze River (MRYTR) & Hubei, Hunan, Jiangxi and Anhui \\
Southwest China (SWC) & Yunnan, Guizhou, Sichuan, Chongqing and Guangxi \\
Northwest China (NWC) & Gansu, Qinghai, Ningxia, Xizang(Tibet) and Xinjiang \\
\hline
\end{tabular}

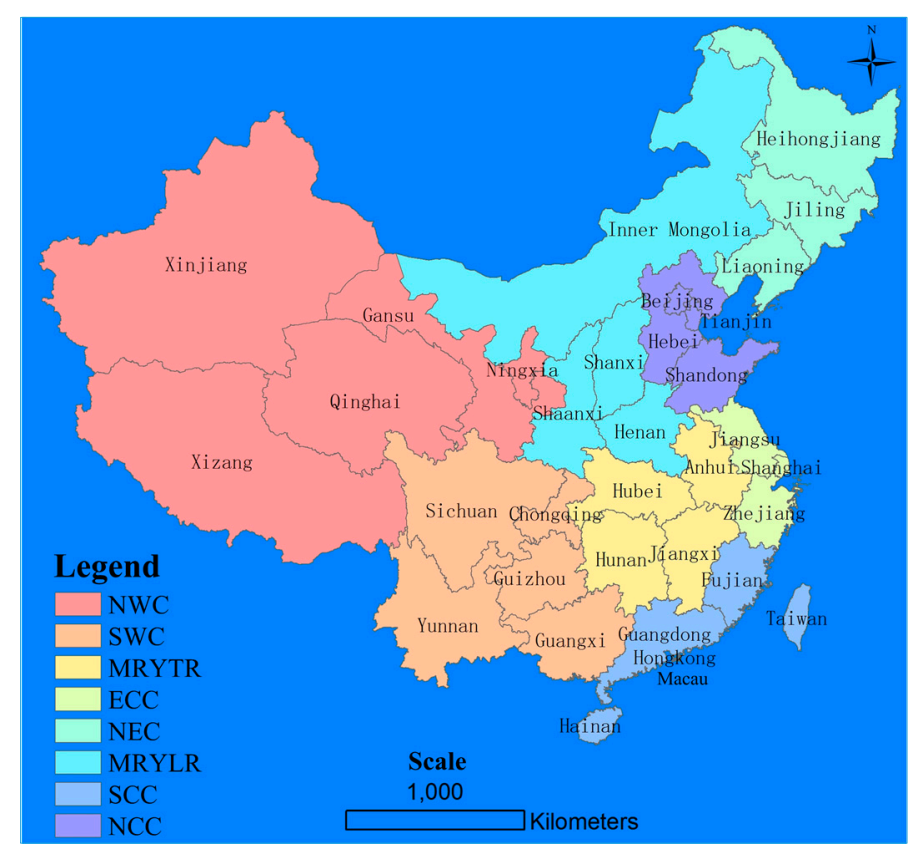

Figure 1. The distribution of provincial regions and economic regions in this study. South China Sea Islands are not included in this map as they are excluded from analysis in this study and this map is not a map for the entire regions of China. 
Table 2. Number of prefectural cities in the 31 provinces (excluding Hongkong, Macau, and Taiwan).

\begin{tabular}{cccc}
\hline Province & Number of Prefectural Cities & Province & Number of Prefectural Cities \\
\hline Anhui & 17 & Jiangxi & 11 \\
Beijing & 1 & Jilin & 9 \\
Chongqing & 1 & Liaoning & 14 \\
Fujian & 9 & Ningxia & 4 \\
Gansu & 14 & Qinghai & 8 \\
Guangdong & 22 & Shaanxi & 10 \\
Guangxi & 13 & Shandong & 17 \\
Guizhou & 9 & Shanghai & 1 \\
Hainan & 18 & Shanxi & 11 \\
Hebei & 11 & Sichuan & 21 \\
Heilongjiang & 13 & Tianjin & 1 \\
Henan & 17 & Xinjiang & 15 \\
Hubei & 15 & Xizang & 7 \\
Hunan & 13 & Yunnan & 16 \\
Inner Mongolia & 12 & Zhejiang & 11 \\
Jiangsu & 13 & - & - \\
\hline
\end{tabular}

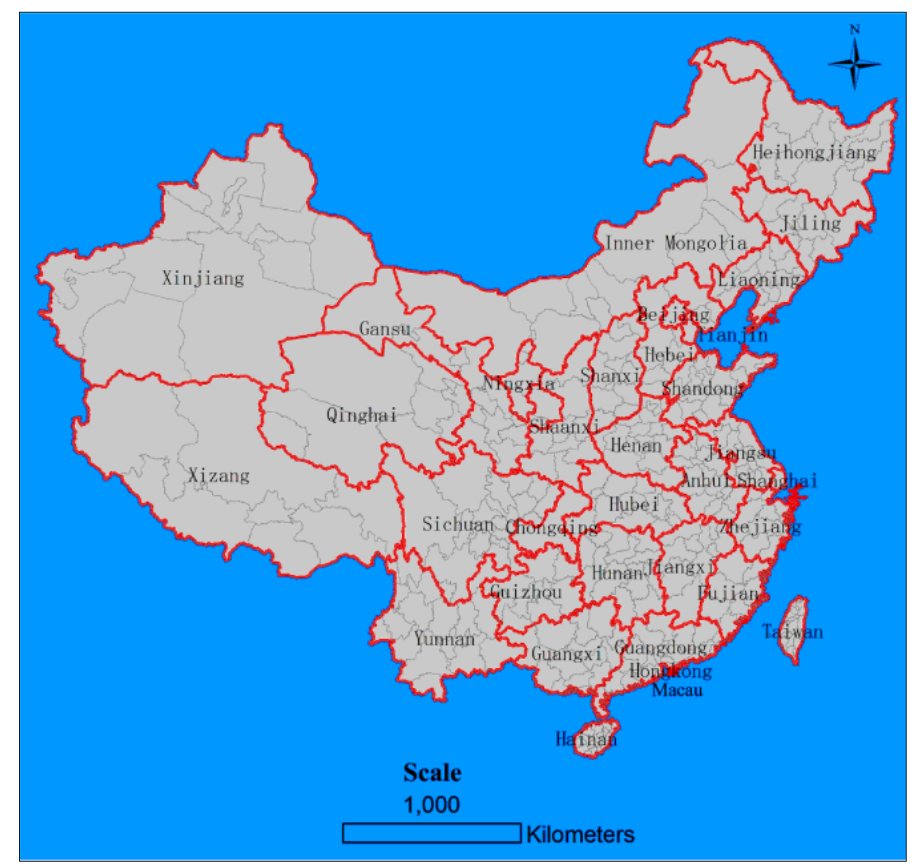

Figure 2. The distribution of the prefectural regions of China. South China Sea Islands are not included in this map as they are excluded from analysis in this study and this map is not a map for the entire regions of China.

Population density grid and night light imagery were used to calculate regional inequality. The population grid images with a spatial resolution of $1 \mathrm{~km}$ for 2005 and 2010 were downloaded from Global Change Research Data Publisher \& Repository [62]. The population grids describe the residential population but not the registered population (Hukou population), so that it represents where people actually live. 
The night light images for 2005 and 2010, with a spatial resolution of about $1 \mathrm{~km}$, were derived from the annual composite product of Defense Meteorological Satellite Program's Operational Linescan System (DMSP/OLS), and were downloaded from National Geophysical Data Center [63]. To avoid radiometric problems such as over-saturation that occurs in urban centers [64,65], we used the radiance calibrated product. Compared to the traditional DMSP/OLS stable products [66], the radiance calibrated product provides much better radiometric attributes so that it quantifies the actual night light more accurately. Unfortunately, the radiance calibrated product is not available for 2005 . However, the data for 2004 and 2006 are available, so we generated an estimated radiance calibrated product for 2005 by averaging the products from 2004 and 2006. This averaging operation can be viewed as simple linear interpolation to estimate the night light in 2005. It is worth noting that the radiance calibrated product is deemed to be unitless. All the geographic data were projected to the Albers Conical Equal Area Projection.

\subsection{Aggregating Night Light Images and Population Grids}

A previous study showed that the DMSP/OLS night light images have a spatial error of about $2 \mathrm{~km} \mathrm{[67].}$ Although that study did not utilize the radiance calibrated products we used, we should be cautious regarding the potential spatial mismatch between the night light images and population grids. To reduce the spatial mismatch, we aggregated the data using an $8 \times 8$ pixel window, producing night light and population data on an $8 \mathrm{~km}$ grid. Thus the spatial error is likely much less than 0.5 pixel. Although some spatial details are suppressed after the aggregation process, the general difference between the night light and population grid remains, and thus the aggregated data are still effective to measure the regional inequality. The population density grids for 2005 and 2010 are shown in Figures 3 and 4, and the night light images are shown in Figures 5 and 6.

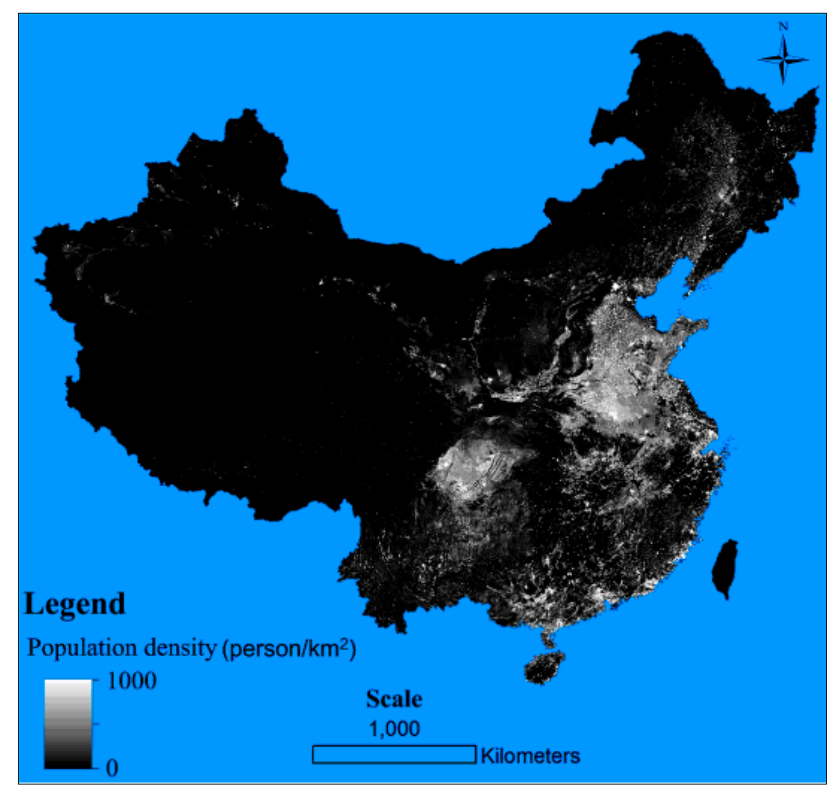

Figure 3. The population density grid data of China for 2005. The population density of 1000 persons $/ \mathrm{km}^{2}$ and larger was assigned the maximum brightness. Taiwan, Hongkong, and Macau are all in black color due to lack of data. South China Sea Islands are not included in this map as they are excluded from analysis in this study and this map is not a map for the entire regions of China. 


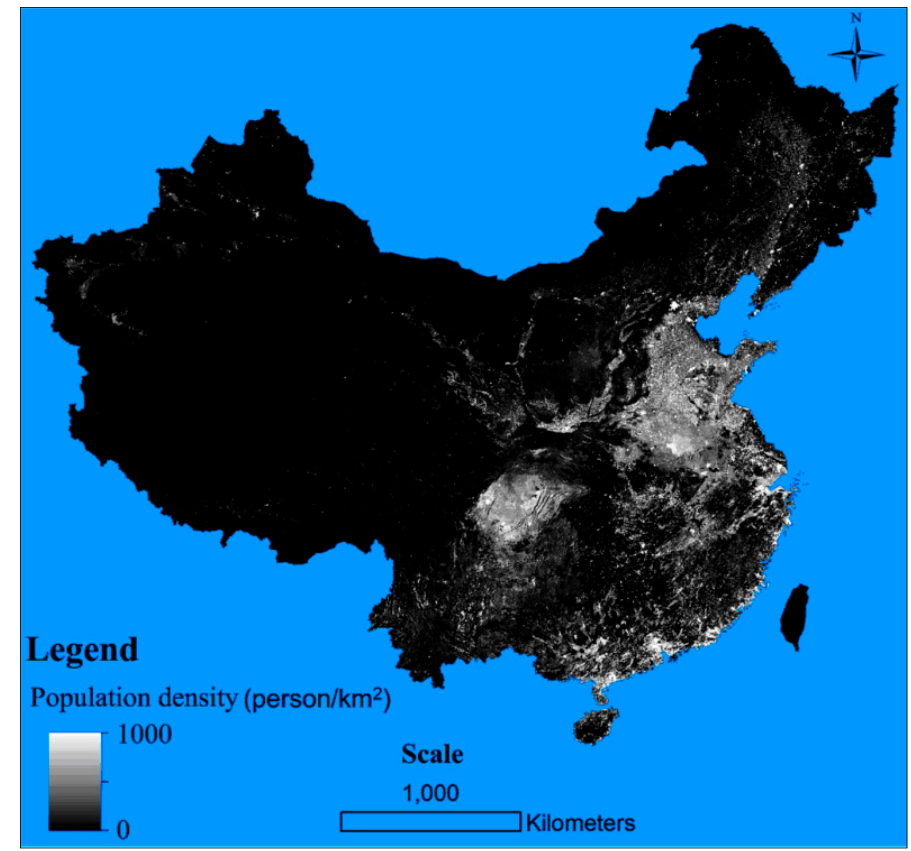

Figure 4. The population density grid data of China for 2010. The population density of 1000 persons $/ \mathrm{km}^{2}$ and larger was assigned the maximum brightness. Taiwan, Hongkong, and Macau are all in black color due to lack of data. South China Sea Islands are not included in this map as they are excluded from analysis in this study and this map is not a map for the entire regions of China.

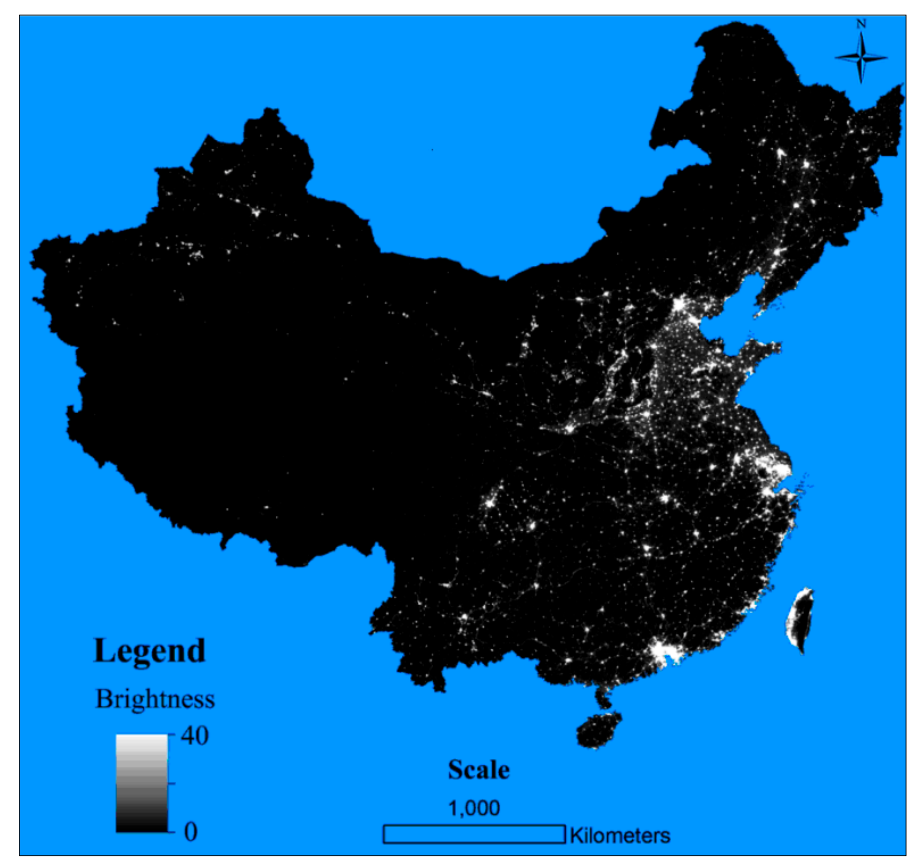

Figure 5. The DMSP/OLS (Defense Meteorological Satellite Program's Operational Linescan System) night light imagery of China for 2005. Note: the brightness of 40 and larger was assigned the maximum brightness. South China Sea Islands are not included in this map as they are excluded from analysis in this study and this map is not a map for the entire regions of China. 


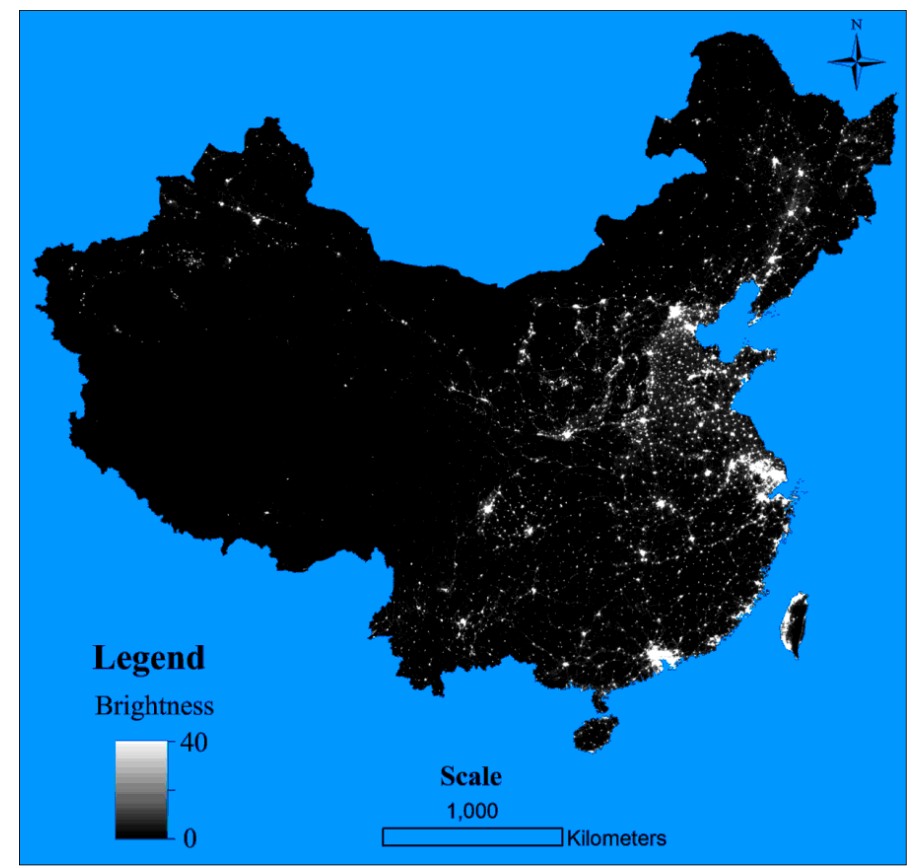

Figure 6. The DMSP/OLS night light imagery of China for 2010. Note: the brightness of 40 and larger was assigned the maximum brightness. South China Sea Islands are not included in this map as they are excluded from analysis in this study and this map is not a map for the entire regions of China.

\section{Methodology}

We employed the Night Light Development Index (NLDI) to measure the regional inequality of public services from population density grid and night light [56]. The NLDI is based on the concept of the Gini Coefficient that (1) the regional inequality is high if a minority of residents live in an area producing the majority of the night light; (2) the regional inequality is low if the spatial distribution of night light is highly consistent with the spatial distribution of the population density [56]; and (3) the NLDI is between 0 and 1, where 0 represents perfect equality and 1 represents extreme inequality.

The following three steps were conducted to calculate the NLDI for a certain region. First, areas with a zero population density were excluded from the analysis, since such areas are not relevant to our study. Second, a Lorenz Curve was extracted, showing the relationship between cumulative population and cumulative night light. Finally, the Lorenz Curve was used to calculate the NLDI, as shown in Figure 7.

The NLDI for Mainland China as a whole, the eight economic regions, the 31 provincial regions, and the 354 prefectural regions were extracted for both 2005 and 2010. As an example, the Lorenz Curve for Mainland China for 2005 is presented in Figure 8. 


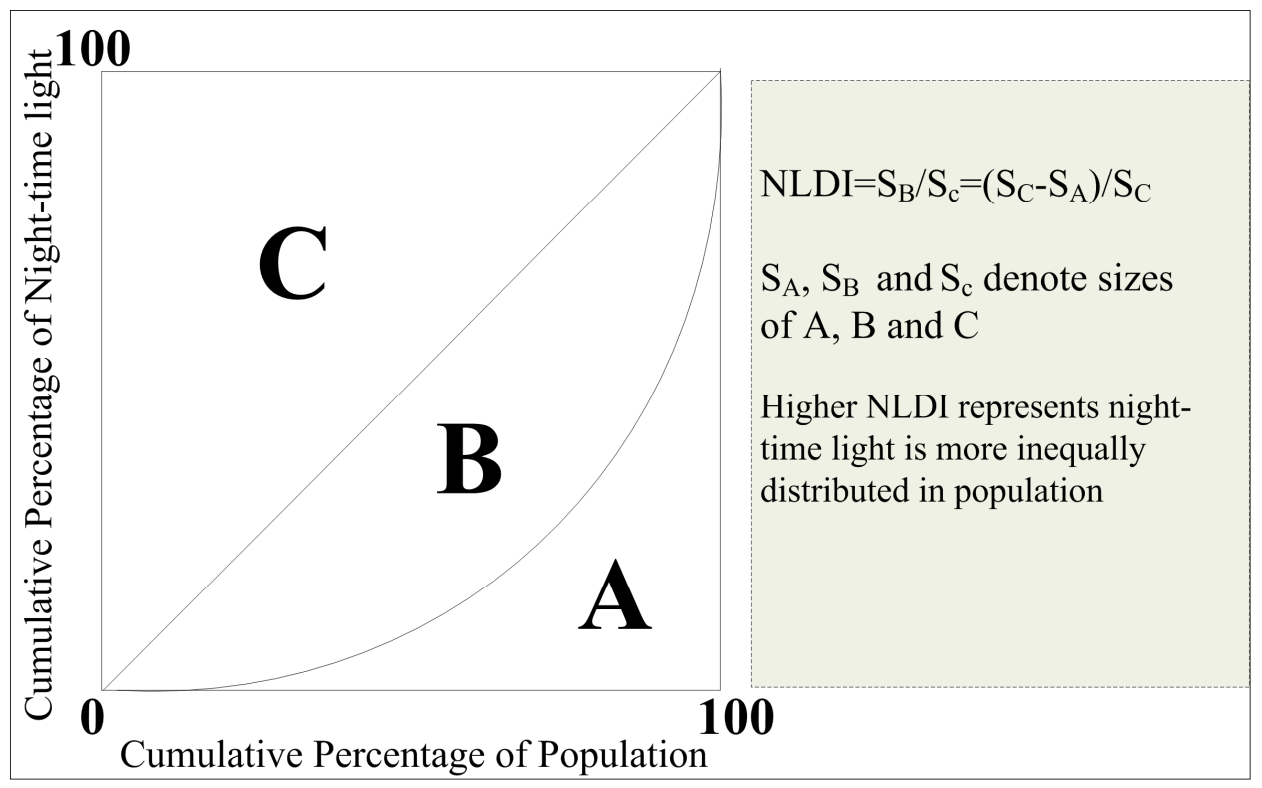

Figure 7. The Night Light Development Index (NLDI) based on the Lorenz Curve.

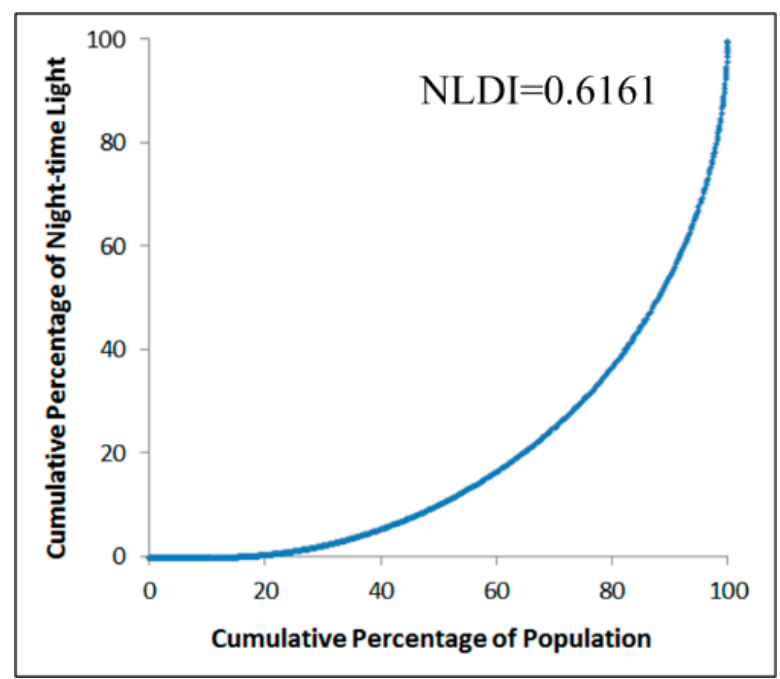

Figure 8. The Lorenz Curve of Mainland China for 2005.

\section{Results and Discussion}

\subsection{Regional Inequality of the Economic Regions}

The NLDI for Mainland China and the eight economic regions was derived as shown in Table 3 and Figures 9 and 10. NLDI values of the eight economic regions range from 0.4572 to 0.7251 for 2005 and from 0.4312 to 0.6678 for 2010 , showing the regional inequality varies among different economic regions. Southwest China (SWC) and Northwest China (NWC), the least developed regions in China, have the highest NLDI for both 2005 and 2010. Northern Coastal China (NCC) and Eastern Coastal China (ECC) have the lowest NLDI for both 2005 and 2010, indicating these regions have the most equally distributed public services. 
The patterns of NLDI change between 2005 and 2010 were summarized by categorizing change in three classes:

$$
\mathrm{NLDI}_{\text {change }}=\left\{\begin{array}{c}
\text { increase: } \mathrm{NLDI}_{2010}-\mathrm{NLDI}_{2005} \geq 0.01 \\
\text { constant: } 0.01>\mathrm{NLDI}_{2010}-\mathrm{NLDI}_{2005} \geq-0.01 \\
\text { decrease: }-0.01>\mathrm{NLDI}_{2010}-\mathrm{NLDI}_{2005}
\end{array}\right.
$$

NLDI decreased in seven out of eight economic zones (i.e., NCC, MRYLR, NEC, MRYTR, SCC, SWC, and NWC), indicating an increase in the equality of public services. Among these regions, Northwest China had the largest NLDI decline, indicating that regional equality was most improved in this region. Eastern Coastal China (ECC) is the only region with an NLDI increase, indicating that the regional inequality increased during the period. For Mainland China as a whole, NLDI declined from 0.6161 to 0.5743 between 2005 and 2010, indicating that public services became more equally distributed over Mainland China during this period.

Table 3. NLDI of Mainland China and the eight economic regions for 2005 and 2010.

\begin{tabular}{cccc}
\hline Region & NLDI $2005^{2}$ & NLDI $_{2010}$ & NLDI Change \\
\hline Mainland China & 0.6161 & 0.5743 & Decrease \\
Northern Coastal China (NCC) & 0.4775 & 0.4312 & Decrease \\
Eastern Coastal China (ECC) & 0.4572 & 0.4882 & Increase \\
Middle Reaches of the Yellow River (MRYLR) & 0.5548 & 0.5190 & Decrease \\
Northeast China (NEC) & 0.5222 & 0.4811 & Decrease \\
Middle Reaches of the Yangtze River (MRYTR) & 0.5798 & 0.5421 & Decrease \\
Southern Coastal China (SCC) & 0.6639 & 0.6081 & Decrease \\
Southwest China (SWC) & 0.7116 & 0.6678 & Decrease \\
Northwest China (NWC) & 0.7251 & 0.6304 & Decrease \\
\hline
\end{tabular}

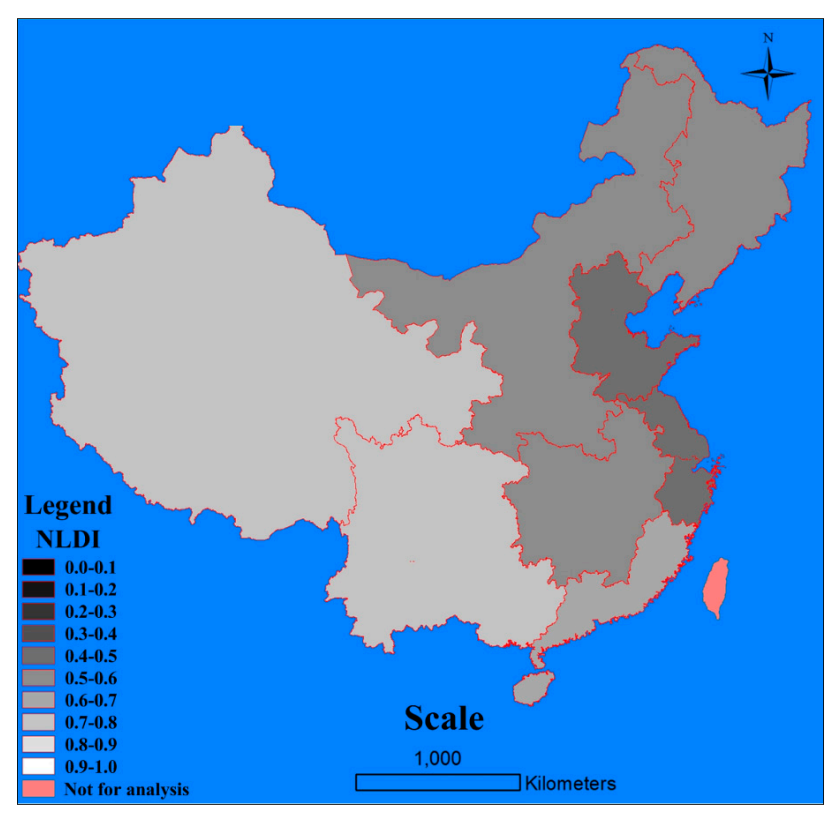

Figure 9. Night light development index (NLDI) of the eight economic zones for 2005. South China Sea Islands are not included in this map as they are excluded from analysis in this study and this map is not a map for the entire regions of China. 


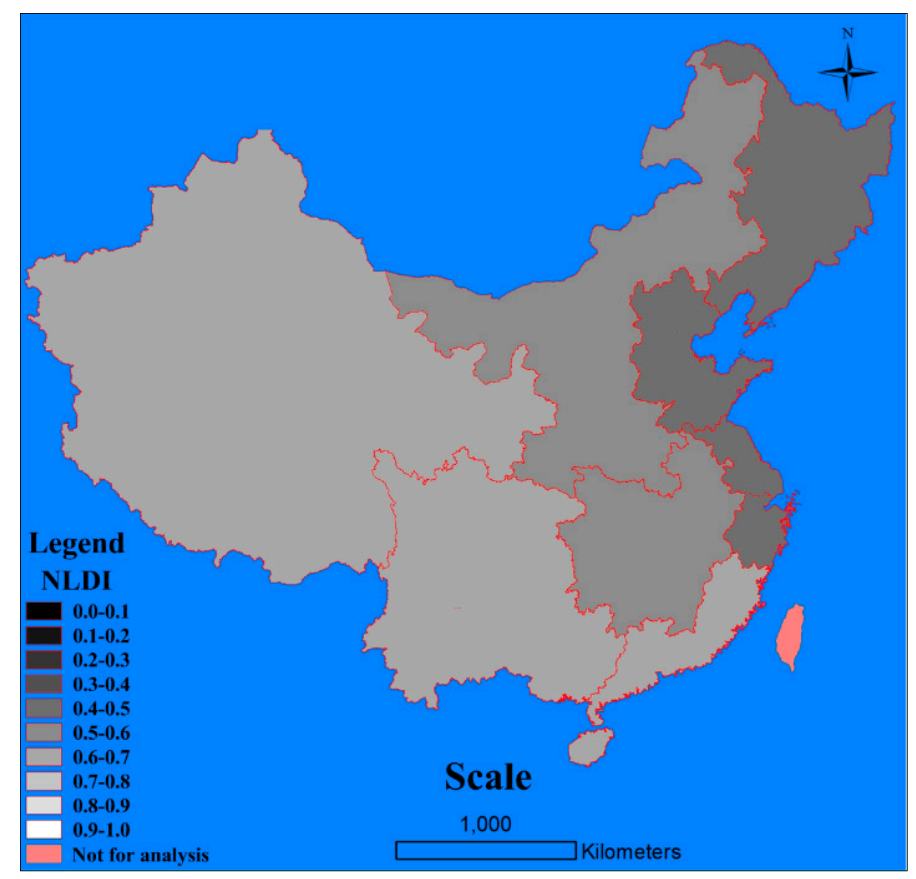

Figure 10. Night light development index (NLDI) of the eight economic zones for 2010. South China Sea Islands are not included in this map as they are excluded from analysis in this study and this map is not a map for the entire regions of China.

\subsection{The Regional Inequality of Provincial Regions}

The NLDI of the 31 provinces for 2005 and 2010 are shown in Table 4 and in Figures 11 and 12.

Table 4 shows that Beijing, Shanghai, Tianjin, Hebei, and Liaoning have the lowest NLDI values for 2005, indicating public services were most equally distributed in these regions at that time. For 2010, the lowest NLDI provinces were Beijing, Shanghai, Shandong, Hebei, and Henan. In contrast, Sichuan, Yunnan, Guangxi, Gansu, and Xizang (Tibet) have the highest NLDI for 2005. But in 2010, the highest NLDI provinces are Xizang, Sichuan, Guizhou, Inner Mongolia, and Chongqing for 2010. These highest NLDI provinces, except Inner Mongolia, are all located in Southwest China (SWC) and Northwest China (NWC) for both 2005 and 2010, emphasizing the patterns previously found in the economic regions, indicating public services are most unequally distributed in SWC and NWC. Specifically, Xizang is the only provincial region with NLDI larger than 0.8 for both 2005 and 2010. Comparing the NLDI data for 2005 and 2010 using the categorization in Equation (1), we found that nine provinces have increased NLDI, one province has constant NLDI, and 21 provinces have decreased NLDI. This finding shows that the number of provinces becoming more equal is larger than the number of provinces becoming more unequal. Among the ten provinces in Southwest China and Northwest China, nine provinces decreased NLDI during 2005-2010, and only one province (Chongqing) increased NLDI. This trend demonstrates that the regional inequality of Western China was reduced during the period.

We also generated histograms of the NLDI of the provinces to investigate their distribution as shown in Figure 13. We found that the provincial NDLI is concentrated in the range $0.3-0.7$ for both 2005 and 2010. By comparing the two histograms, the number of provinces with NLDI between 0.7 and 0.8 has 
been greatly reduced, from three provinces to zero. This reduction is a major contribution of NLDI reduction over Mainland China.

Table 4. The NLDI of the 31 provinces for 2005 and 2010.

\begin{tabular}{cccccccc}
\hline Province & NLDI 2005 & NLDI $2010_{20}$ & NLDI Change & Province & NLDI $2005^{2}$ & NLDI 2010 & NLDI Change \\
\hline Beijing & 0.2861 & 0.3526 & Increase & Ningxia & 0.5956 & 0.5833 & Decrease \\
Shanghai & 0.3076 & 0.3045 & Constant & Shaanxi & 0.5989 & 0.5708 & Decrease \\
Tianjin & 0.3181 & 0.4087 & Increase & Chongqing & 0.6248 & 0.6434 & Increase \\
Hebei & 0.3634 & 0.3854 & Increase & Jiangxi & 0.6287 & 0.5817 & Decrease \\
Liaoning & 0.3899 & 0.4419 & Increase & Jilin & 0.6471 & 0.4635 & Decrease \\
Zhejiang & 0.4047 & 0.4944 & Increase & Inner Mongolia & 0.6574 & 0.6476 & Constant \\
Shandong & 0.4186 & 0.3796 & Decrease & Qinghai & 0.6657 & 0.5838 & Decrease \\
Shanxi & 0.4422 & 0.4070 & Decrease & Xinjiang & 0.6689 & 0.6045 & Decrease \\
Fujian & 0.4504 & 0.5173 & Increase & Guizhou & 0.6858 & 0.6559 & Decrease \\
Jiangsu & 0.4628 & 0.4931 & Increase & Guangdong & 0.6969 & 0.6323 & Decrease \\
Henan & 0.4703 & 0.3708 & Decrease & Sichuan & 0.6998 & 0.6740 & Decrease \\
Hainan & 0.5181 & 0.4463 & Decrease & Yunnan & 0.7013 & 0.6497 & Decrease \\
Heihongjiang & 0.5440 & 0.5171 & Decrease & Guangxi & 0.7278 & 0.6233 & Decrease \\
Hunan & 0.5475 & 0.5737 & Increase & Gansu & 0.7862 & 0.5979 & Decrease \\
Hubei & 0.5629 & 0.4971 & Decrease & Xizang & 0.8531 & 0.8292 & Decrease \\
Anhui & 0.5716 & 0.5048 & Decrease & - & - & - & - \\
\hline
\end{tabular}

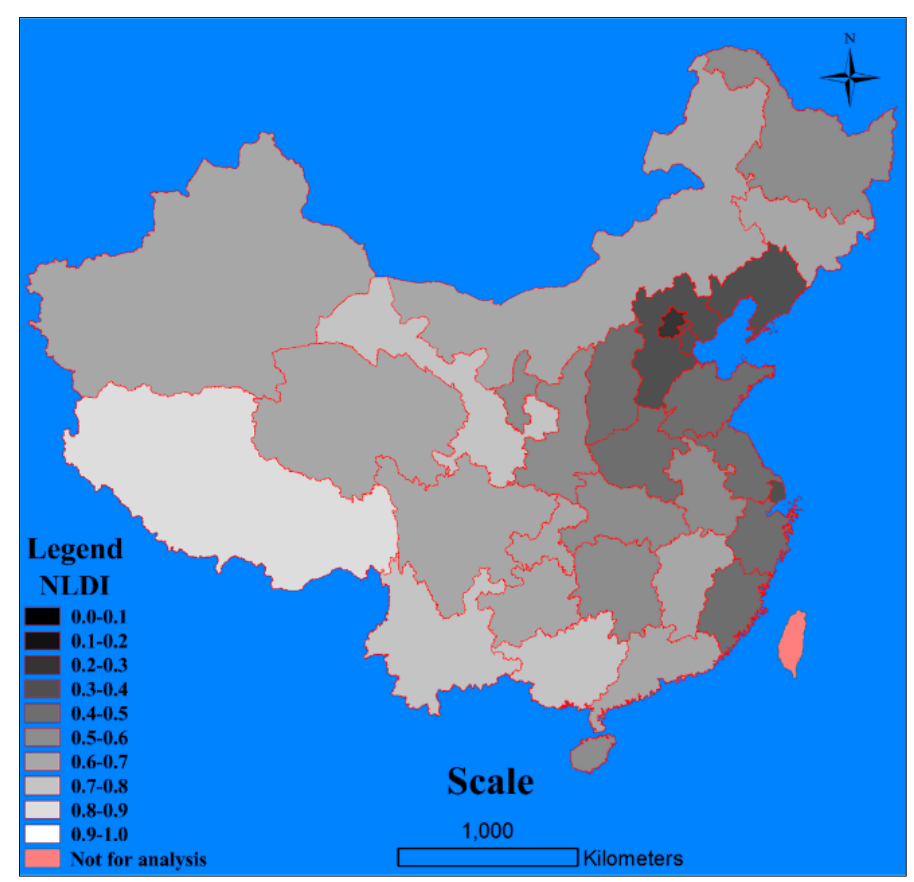

Figure 11. Night light development index (NLDI) of the 31 provinces for 2005. South China Sea Islands are not included in this map as they are excluded from analysis in this study and this map is not a map for the entire regions of China. 


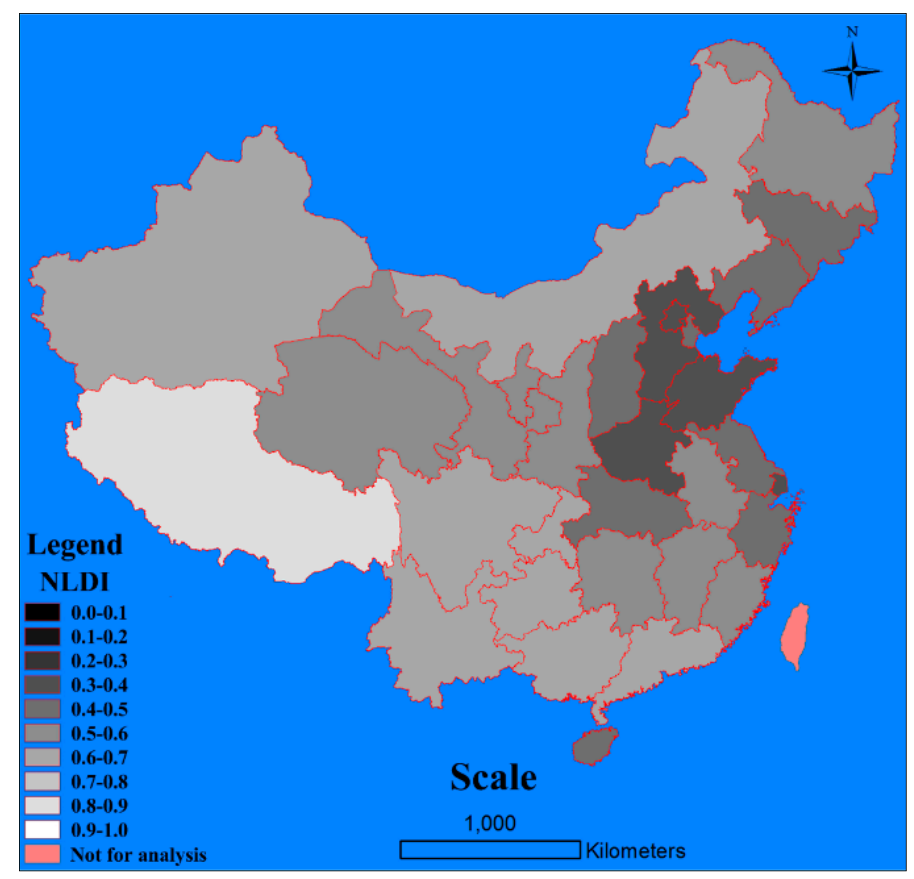

Figure 12. Night light development index (NLDI) of the 31 provinces for 2010. South China Sea Islands are not included in this map as they are excluded from analysis in this study and this map is not a map for the entire regions of China.

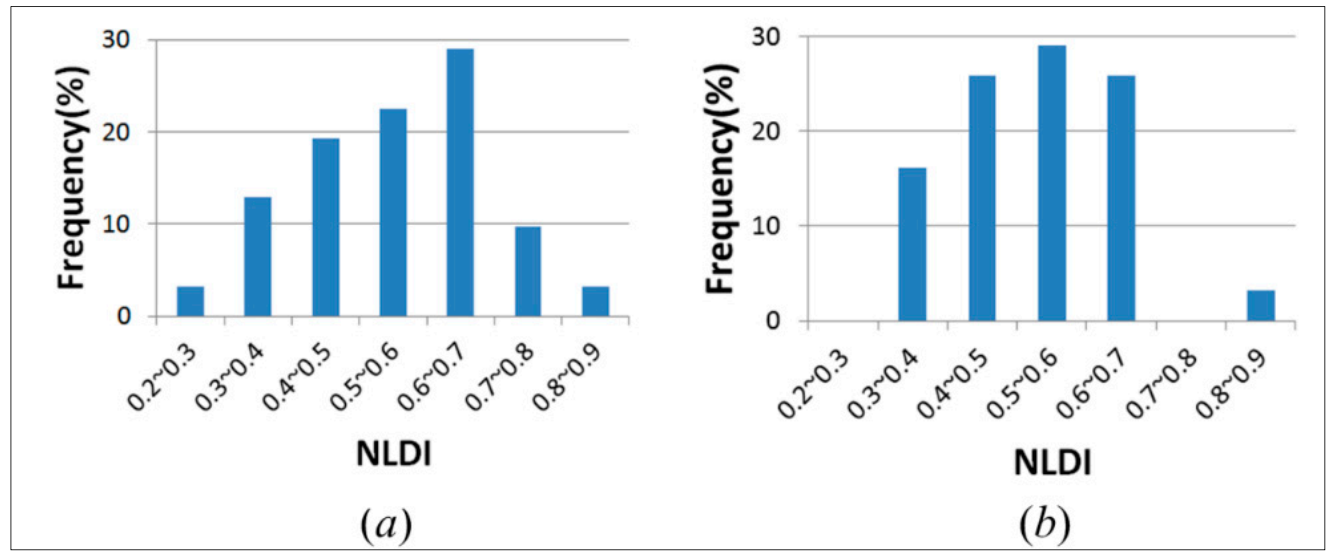

Figure 13. The statistical distribution of NLDI of 31 provinces: (a) NLDI frequency for 2005; (b) NLDI frequency for 2010.

We hypothesize that the regional inequality at the provincial scale shown in Figures 11, 12 is related to population density variations: Beijing, Shanghai, Shandong, Tianjin, and Henan with low NLDI are all densely populated regions, while Yunnan, Guizhou, Gansu, and Xizang with high NLDI are all sparsely populated regions. Empirical evidence suggests sparsely populated regions in China tend to be less developed. As a consequence, low night light per capita tends to be associated with high NLDI. To test these hypotheses, we regressed population density and NLDI, and night light per capita and NLDI. Areas with no residents were excluded from the analysis. The best function for the regression was found to be a power function. The regression results are shown in Figure 14. 


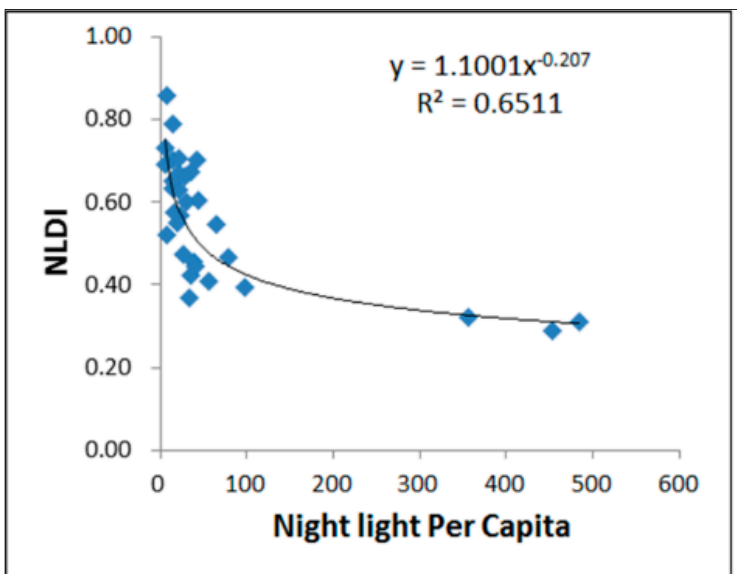

(a)

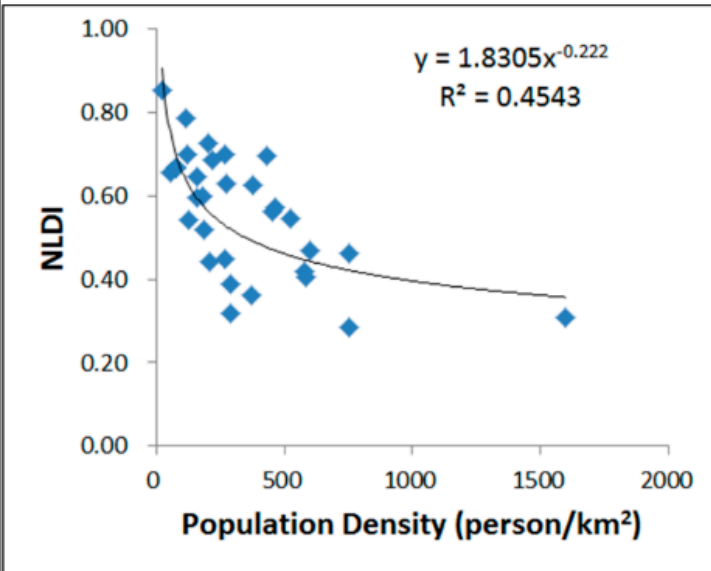

(c)

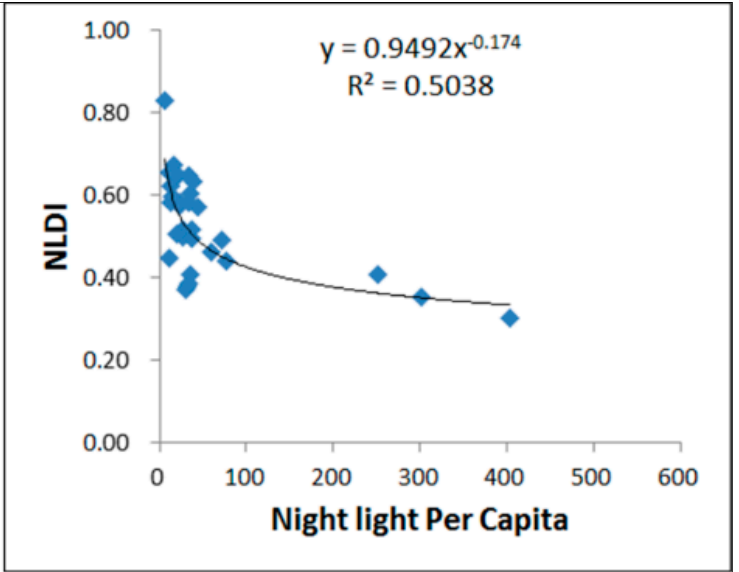

(b)

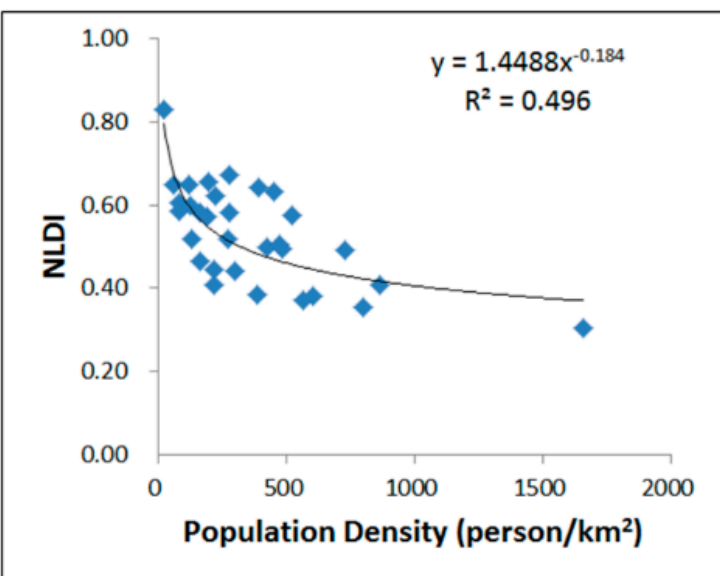

$(d)$

Figure 14. The regression analysis for 31 provinces: (a) night light per capita versus NLDI for 2005; (b) night light per capita versus NLDI for 2010; (c) population density versus NLDI for 2005; and (d) population density versus NLDI for 2010.

From Figure 14, we find that the night light per capita has a strong relationship with NLDI; the regression analyses for 2005 and 2010 have $R^{2}$ of 0.6511 and 0.5038 , respectively. This analysis suggests that a provincial region with more public services per capita has more equally distributed public services. In addition, the population density also has a relationship with NLDI, suggesting that regions of higher population density have more equally distributed public services, although this relationship is less strong, with $\mathrm{R}^{2}$ values of 0.4543 and 0.496 for 2005 and 2010, respectively.

\subsection{The Regional Inequality of Prefectural Regions}

The NLDI of the 354 prefectural cities for 2005 and 2010 is mapped in Figures 15, 16 (see the Appendix of the tabulated data). We found that Jiayuguan City (Gansu Province), Lingshui County (Hainan Province), and Zaozhuang City (Shandong Province) are the three prefectural cities with the lowest NLDI in 2005 and the inferred most equal public services, and these cities have a low NLDI in 2010. Bazhong City (Sichuan Province), Changdu Area (Xizang), and Zhangye City (Gansu Province) are the three prefectural cities with the highest NLDI in 2005 and the most unequal public services. Bazhong City and Changdu Area remain the most unequal in 2010, while the NLDI in Zhangye City 
was greatly reduced from 0.9456 to 0.5806 . Using the definition given by Equation (1), we found that 95 out of the 354 prefectural cities indicate an NLDI increase during 2005-2010, 219 cities indicate an NLDI decrease during 2005-2010, and 40 cities indicate a constant NLDI during the period. This finding shows that the number of prefectural cities becoming more equal is larger than those becoming more unequal during 2005-2010. As shown in Figures 15 and 16, the spatial distribution of NLDI at a prefectural scale is similar to that of the provincial scale as shown in Figures 11 and 12-Beijing, Tianjin, Hebei, and Shandong (all located in Northern Coastal China) have a low NLDI, where the Southwest and Northwest China have a high NLDI for both 2005 and 2010.

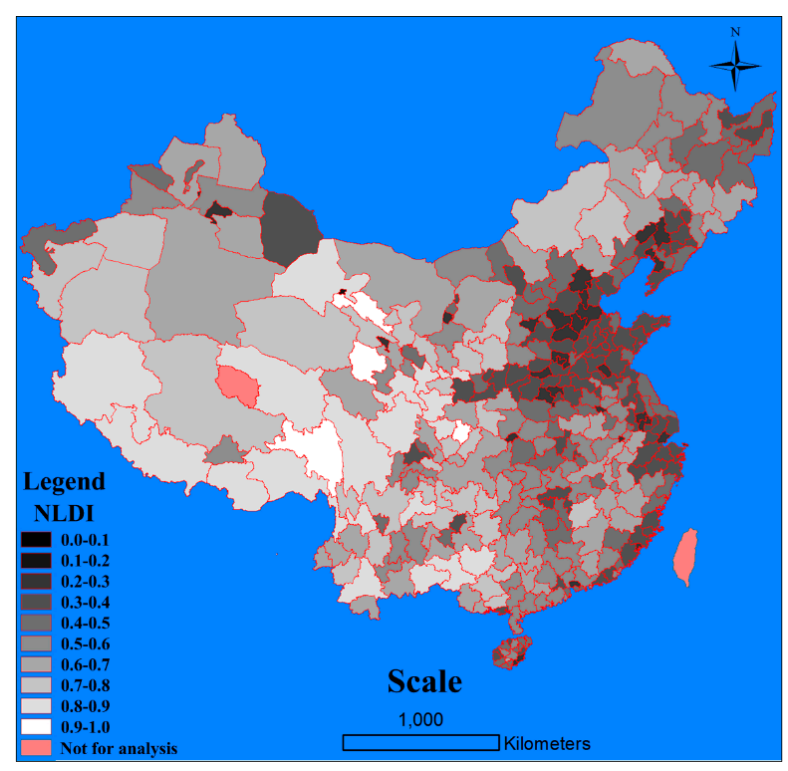

Figure 15. Night light development index (NLDI) of the 354 prefectural cities for 2005. South China Sea Islands are not included in this map as they are excluded from analysis in this study and this map is not a map for the entire regions of China.

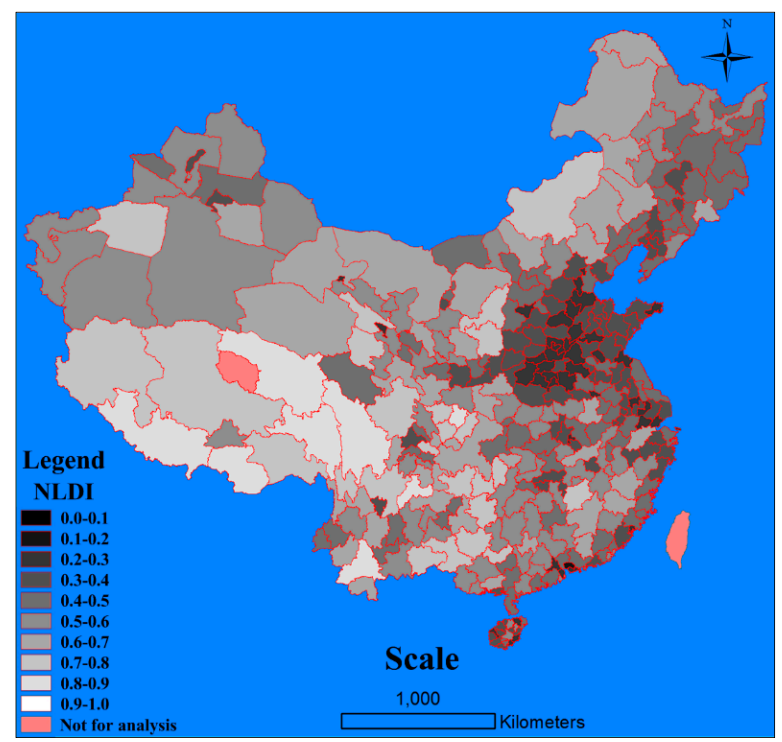

Figure 16. Night light development index (NLDI) of the 354 prefectural cities for 2010. South China Sea Islands are not included in this map as they are excluded from analysis in this study and this map is not a map for the entire regions of China. 
To see the statistical distribution of the NLDI of the 354 prefectural cities, histograms were generated for 2005 and 2010, as shown in Figure 17. We found that the distribution of the NLDI at the prefectural city scale is not as concentrated as the results at the provincial scale. The number of prefectural cities with very high NLDI (0.8-0.9 and 0.9-1.0) was notably reduced from 2005 to 2010, which contributed to the reduction of NLDI for most of the prefectural cities.

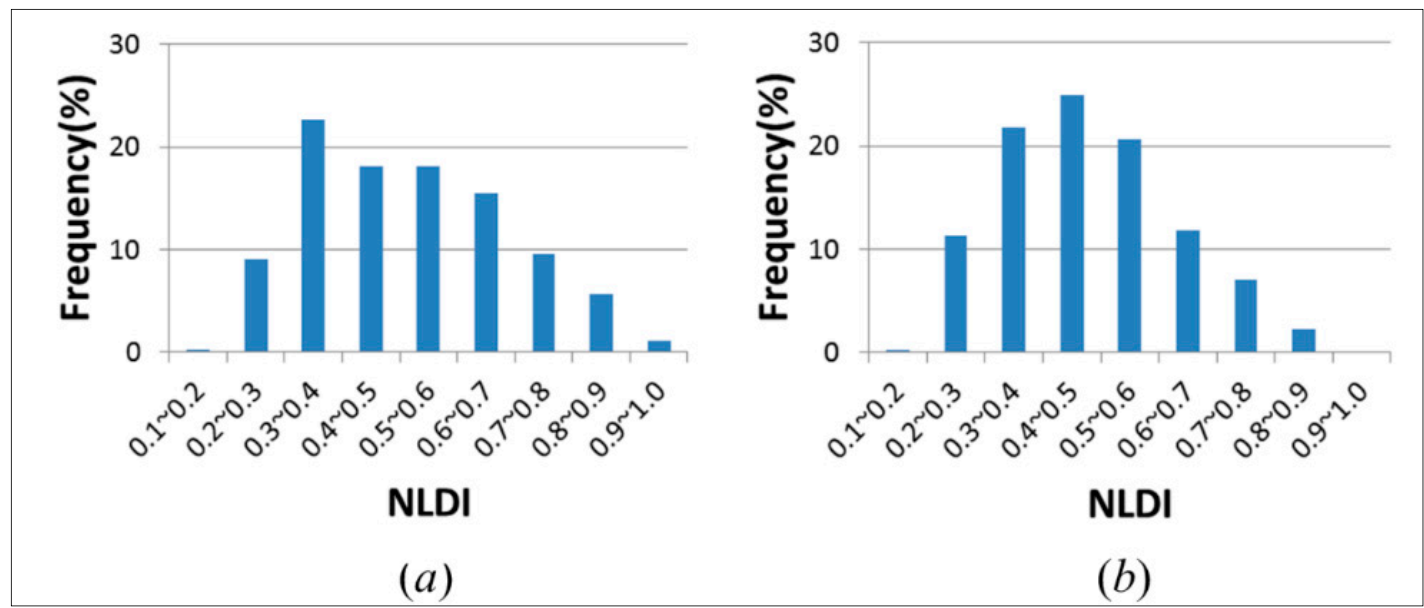

Figure 17. The statistical distribution of NLDI of 354 prefectural cities: (a) NLDI frequency for 2005; and (b) NLDI frequency for 2010.

As shown in Figure 18, night light per capita and population density is related to NLDI at the provincial scale. From Figure 18a,b we find that the night light per capita is related to the NLDI with $\mathrm{R}^{2}$ values of 0.4912 and 0.3936 for 2005 and 2010, respectively, suggesting higher public services per capita are associated with more equal public services. Similarly, Figure 18c,d show that the population density is related to NLDI, with $R^{2}$ values of 0.3682 and 0.4082 for 2005 and 2010, respectively, again emphasizing the interpretation that regions with higher population density have more equal public services.

As shown in Table 5, we calculated the number of prefectural cities with NLDI $>0.8$ in each province as an index to highlight the distribution of cities with highly unequal public services. There were a total of 25 prefectural cities with NLDI > 0.8 in 2005 and 11 in 2010, showing that the number of prefectural cities with very unequal public services was greatly reduced during this period. These cities are distributed in six provinces for 2005 and four provinces for 2010. For 2005, we found that Gansu, Sichuan, Xizang, and Yunnan have more than four prefectural cities with NLDI $>0.8$ for each province. It is notably that there was no prefectural city with NLDI $>0.8$ in Gansu province in 2010, despite there having been four such cities in 2005. This finding is highly consistent with the observation that the NLDI of Gansu decreased from 0.7862 to 0.5979 , as shown in Table 4. All the prefectural cities with NLDI $>0.8$ are distributed in Southwest China and Northwest China, which are the regions with highest NLDI as shown in Table 3. 


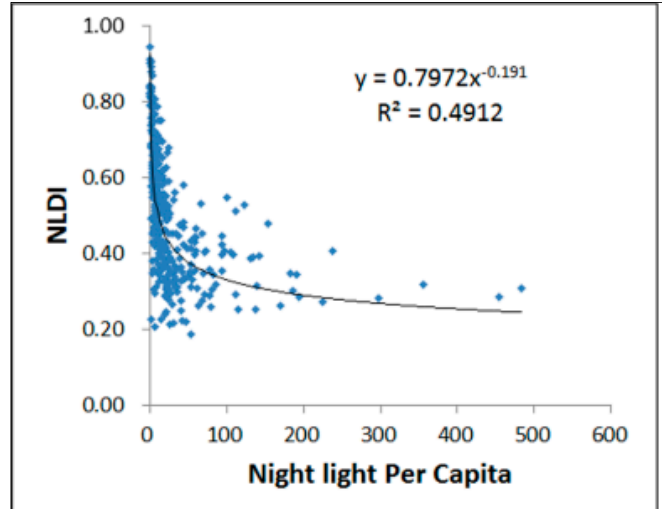

(a)

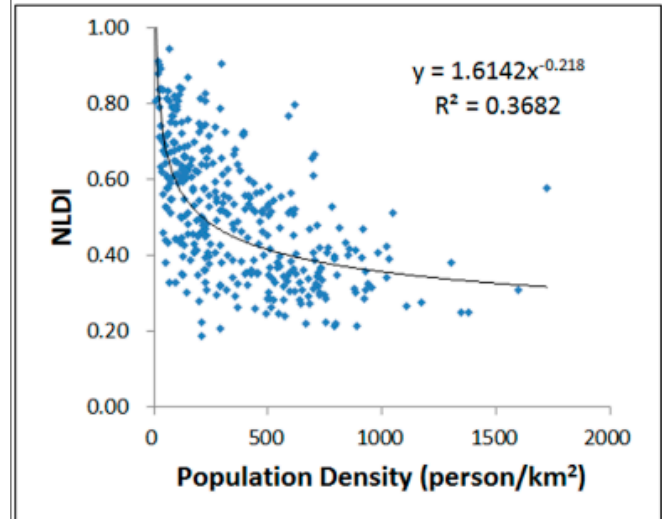

(c)

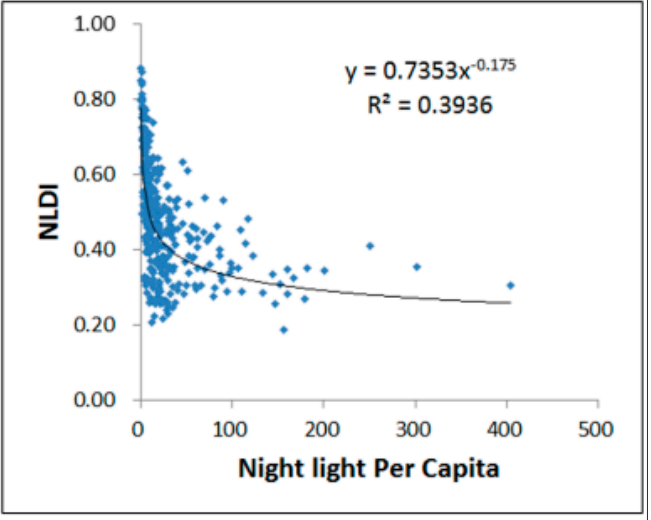

(b)

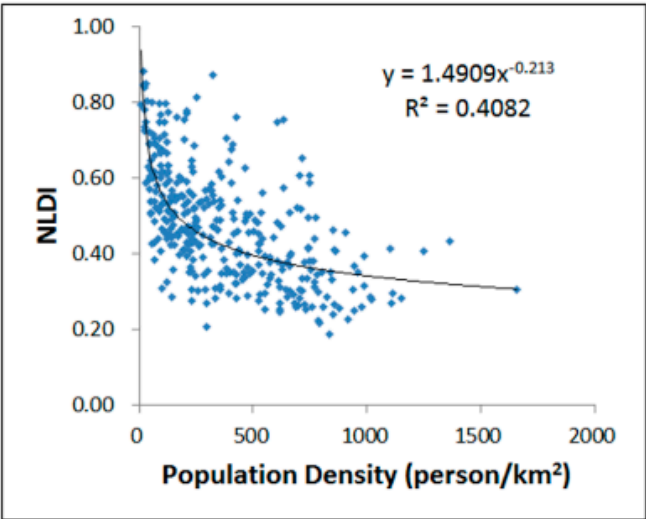

(d)

Figure 18. The regression analysis for 354 prefectural cities: (a) night light per capita versus NLDI for 2005; (b) night light per capita versus NLDI for 2010; (c) population density versus NLDI for 2005; and (d) population density versus NLDI for 2010.

Table 5. Number of prefectural cities with high NLDI (NPCHN) for 2005 and 2010.

\begin{tabular}{cccc}
\hline Province & Economic Zone of the Province & NPCHN2005 $^{2}$ & NPCHN2010 $^{2}$ \\
\hline Gansu & Northwest China (NWC) & 6 & 0 \\
Guangxi & Southwest China (SWC) & 2 & 0 \\
Qinghai & Northwest China (NWC) & 2 & 1 \\
Sichuan & Southwest China (SWC) & 5 & 2 \\
Xizang & Northwest China (NWC) & 5 & 5 \\
Yunnan & Southwest China (SWC) & 5 & 3 \\
\hline & Mainland China & 25 & 11 \\
\hline
\end{tabular}

\section{Conclusions}

Uneven development in China has brought a number of social problems such as poverty [68] and family separation [69], which are obstacles to China's sustainable development. Measuring the regional inequality of China has long been of interest to the social science community. Most of the researches have focused on inter-regional inequality, such as the disparity among different provinces and disparity between Western China and Eastern China. In contrast, less attention has been paid to intra-regional inequality, especially at the city level, because census data is only available as aggregated data for basic units such as the county or city. This study made use of spatially continuous population data 
and satellite-observed night light data to calculate the Night Light Development Index (NLDI) as an indicator of intra-regional inequality of public services. Although NLDI has already been used for the world and China [56,57], our study is the first using regions of multiple scales, in particular at the prefectural city scale, and also for change analysis in China.

The overall finding is that the inequality of public services was reduced in China during the period 2005-2010. This finding was observed at all scales of analysis: China as a whole, the eight economic regions, the 31 provinces, and the 354 prefectural regions. The spatial pattern of this reduction in inequality varies by scale of analysis. At all the economic regions scales, Southwest and Northwest China have the highest NLDI indicating the most unequal distribution of public services, whereas Northern Coast China has the lowest NLDI, indicating the most equal distribution of public services. Similar patterns were found at the provincial scale and prefectural region scale. However, strong contrasts in NLDI values are evident within the individual provinces. For example, Southeast China coastal prefectural regions generally have much lower NLDI values than the immediately adjacent regions. Secondly, although there are several factors likely affecting the regional inequality of public services, we found that night light per capita and population density are two important factors, indicating that regions with higher population density and more public services per capita tend to be associated with more equal public services.

As previous studies have shown that the major contributor to night light is street lighting [59], reasons behind the lack of night light in populated areas can be summarized as follows: (1) road networks are absent or sparsely distributed in the area; and (2) there is insufficient street lighting. For example, in the mountainous areas such as Southwest China, the cost of road construction is very high and the road network is limited. Population density is also an important determinant, since investment in the road network is not cost-efficient if there are very few people who can take advantage of the road network. Similarly, a lack of street lighting is very common in many poor areas and especially in rural areas, where local government cannot afford the expense. Where resources are limited, development is likely in only limited areas, suggesting an increased likelihood of spatially unequal infrastructure. Thus higher night light per capita may result in more equality of the night light. These explanations indicate that night light is a proxy for public services, which is likely to be more equally distributed in densely populated regions and developed regions. The multi-scale analysis indicated that Southwest China and Northwest China became more equal in public services. This improvement may be a result of the China Western Development Project in which China's central government invested greatly in the infrastructure, educational, health care, and economy of Western China. This project was designed to reduce the East-West gap and intra-regional gap in Western China. The night light analysis shows that the intra-regional inequality of Western China has been indeed reduced. However, the regional inequality of Southwest and Northwest China is still high, indicating that there is a long way to go for the China Western Development Project.

Due to limit of population density grid data, this study only analyzed the regional inequality for 2005 and 2010, so the comparison analysis can be taken only for these two years. As more population density grid data will be made accessible, the dynamics of the regional inequality of different regions at a different scale can be studied, and a more comprehensive picture on regional inequality of China's development can be drawn in future studies. 


\section{Author Contributions}

Huimin $\mathrm{Xu}$ designed the research, analyzed the data, and wrote the paper, Hutao Yang designed a part of the research, $\mathrm{Xi}$ Li collected and analyzed some of the data, Huiran Jin helped to polish the language, and Deren Li designed a part of the research.

\section{Acknowledgments}

The authors are grateful for the language improvement work done by Prof. Timothy Warner from West Virginia University. This study was supported by the Natural Science Foundation of Hubei Province (No. ZRY2014001235), China Scholarship Council and a Special Fund by Surveying \& Mapping and Geoinformation Research in the Public Interest (No. 201512026).

\section{Conflicts of Interest}

The authors declare no conflict of interest.

\section{Appendix}

Table A1. 354 prefectural cities for 2005 and 2010.

\begin{tabular}{cccc}
\hline Prefectural City & Province & NLDI $_{\mathbf{2 0 0 5}}$ & NLDI $_{\mathbf{2 0 1 0}}$ \\
\hline Jiayuguan City & Gansu & 0.1871 & 0.2763 \\
Lingshui County & Hainan & 0.2067 & 0.2069 \\
Zaozhuang City & Shandong & 0.2127 & 0.2394 \\
Zhoushan City & Zhejiang & 0.2144 & 0.2163 \\
Tongling City & Anhui & 0.2192 & 0.3070 \\
Jiaxing City & Zhejiang & 0.2216 & 0.2599 \\
Shennongjia Area & Hubei & 0.2245 & 0.4741 \\
Hebi City & Henan & 0.2252 & 0.2232 \\
Xingtai City & Hebei & 0.2394 & 0.2689 \\
Cangzhou City & Hebei & 0.2470 & 0.2912 \\
Langfang City & Hebei & 0.2483 & 0.2466 \\
Changzhou City & Jiangsu & 0.2512 & 0.3326 \\
Shihezi City & Xinjiang & 0.2518 & 0.4350 \\
Panjin City & Liaoning & 0.2586 & 0.3316 \\
Yingkou City & Liaoning & 0.2625 & 0.3632 \\
Taiyuan City & Shanxi & 0.2630 & 0.2541 \\
Huainan City & Anhui & 0.2664 & 0.2486 \\
Dongguan City & Guangdong & 0.2724 & 0.1868 \\
Zhenjiang City & Jiangsu & 0.2736 & 0.2918 \\
Xiamen City & Fujian & 0.2757 & 0.2956 \\
Fuxin City & Liaoning & 0.2789 & 0.4101 \\
Shenyang City & Liaoning & 0.2831 & 0.3438 \\
Pingdingshan City & Henan & 0.2835 & 0.2538 \\
Wulumuqi City & Xinjiang & 0.2841 & 0.3476 \\
Beijing City & Beijing & 0.2861 & 0.3526 \\
\hline & & &
\end{tabular}


Table A1. Cont.

\begin{tabular}{|c|c|c|c|}
\hline Prefectural City & Province & NLDI2005 & NLDI2010 \\
\hline Xuchang City & Henan & 0.2869 & 0.2582 \\
\hline Hengshui City & Hebei & 0.2870 & 0.2756 \\
\hline Xining City & Qinghai & 0.2874 & 0.2966 \\
\hline Shijiazhuang City & Hebei & 0.2915 & 0.3036 \\
\hline Yinchuan City & Ningxia & 0.2917 & 0.3518 \\
\hline Wanning City & Hainan & 0.2950 & 0.2692 \\
\hline Anyang City & Henan & 0.2953 & 0.2640 \\
\hline Jiaozuo City & Henan & 0.2975 & 0.2659 \\
\hline Nanjing City & Jiangsu & 0.3015 & 0.3063 \\
\hline Changjiang County & Hainan & 0.3030 & 0.2854 \\
\hline Baoding City & Hebei & 0.3031 & 0.3644 \\
\hline Changsha City & Hubei & 0.3042 & 0.3370 \\
\hline Linyi City & Shandong & 0.3054 & 0.3717 \\
\hline Jinan City & Shandong & 0.3065 & 0.3062 \\
\hline Shanghai City & Shanghai & 0.3076 & 0.3045 \\
\hline Jinzhou City & Liaoning & 0.3104 & 0.4283 \\
\hline Zibo City & Shandong & 0.3106 & 0.3018 \\
\hline Zhoukou City & Henan & 0.3108 & 0.2586 \\
\hline Tieling City & Liaoning & 0.3108 & 0.4303 \\
\hline Ezhou City & Hubei & 0.3110 & 0.2586 \\
\hline Xinxiang City & Henan & 0.3113 & 0.2828 \\
\hline Wuxi City & Jiangsu & 0.3159 & 0.2807 \\
\hline Tianjin City & Tianjin & 0.3181 & 0.4087 \\
\hline Ningbo City & Zhejiang & 0.3193 & 0.4553 \\
\hline Huaibei City & Anhui & 0.3199 & 0.3351 \\
\hline Yantai City & Shandong & 0.3226 & 0.3517 \\
\hline Qionghai City & Hainan & 0.3233 & 0.3077 \\
\hline Luohe City & Henan & 0.3251 & 0.2283 \\
\hline Taizhou City & Zhejiang & 0.3264 & 0.3773 \\
\hline Weihai City & Shandong & 0.3268 & 0.2971 \\
\hline Shuangyashan City & Heilongjiang & 0.3285 & 0.4079 \\
\hline Jincheng City & Shanxi & 0.3289 & 0.3067 \\
\hline Huzhou City & Zhejiang & 0.3293 & 0.2909 \\
\hline Quanzhou City & Fujian & 0.3298 & 0.4969 \\
\hline Wuhan City & Inner Mongolia & 0.3299 & 0.4218 \\
\hline Tangshan City & Hebei & 0.3335 & 0.3366 \\
\hline Xiangtan City & Hunan & 0.3370 & 0.3813 \\
\hline Putian City & Fujian & 0.3373 & 0.4415 \\
\hline Shaoxing City & Zhejiang & 0.3378 & 0.3529 \\
\hline Yuncheng City & Shanxi & 0.3413 & 0.3064 \\
\hline Suzhou City & Jiangsu & 0.3433 & 0.3504 \\
\hline Tai'an City & Shandong & 0.3438 & 0.2551 \\
\hline Qingdao City & Shandong & 0.3451 & 0.3599 \\
\hline Laiwu City & Shandong & 0.3458 & 0.3301 \\
\hline Xian City & Shaanxi & 0.3469 & 0.3258 \\
\hline
\end{tabular}


Table A1. Cont.

\begin{tabular}{|c|c|c|c|}
\hline Prefectural City & Province & NLDI2005 & NLDI2010 \\
\hline Dongfang City & Hainan & 0.3470 & 0.3269 \\
\hline Liaoyang City & Liaoning & 0.3479 & 0.3484 \\
\hline Fushun City & Liaoning & 0.3482 & 0.4309 \\
\hline Shangqiu City & Henan & 0.3483 & 0.2610 \\
\hline Weinan City & Shaanxi & 0.3512 & 0.3220 \\
\hline Luoyang City & Henan & 0.3516 & 0.2814 \\
\hline Binzhou City & Shandong & 0.3519 & 0.3379 \\
\hline Hegang City & Heilongjiang & 0.3520 & 0.4583 \\
\hline Hangzhou City & Zhejiang & 0.3528 & 0.6090 \\
\hline Dezhou City & Shandong & 0.3551 & 0.3817 \\
\hline Beihai City & Guangdong & 0.3558 & 0.3237 \\
\hline Handan City & Hebei & 0.3566 & 0.3441 \\
\hline Pingxiang City & Jiangxi & 0.3566 & 0.3373 \\
\hline Chengdu City & Sichuan & 0.3571 & 0.3164 \\
\hline Quzhou City & Zhejiang & 0.3609 & 0.3440 \\
\hline Liaocheng City & Shandong & 0.3613 & 0.2713 \\
\hline Sanmenxia City & Henan & 0.3619 & 0.3524 \\
\hline Benxi City & Liaoning & 0.3631 & 0.4695 \\
\hline Lianyungang City & Jiangsu & 0.3655 & 0.2868 \\
\hline Jining City & Shandong & 0.3664 & 0.3137 \\
\hline Weifang City & Shandong & 0.3669 & 0.3193 \\
\hline Heze City & Shandong & 0.3686 & 0.2983 \\
\hline Jinhua City & Zhejiang & 0.3692 & 0.3998 \\
\hline Shanwei City & Guangdong & 0.3718 & 0.3126 \\
\hline Liaoyuan City & Jilin & 0.3767 & 0.3427 \\
\hline Huaiyin City & Jiangsu & 0.3806 & 0.3955 \\
\hline Lin'gao County & Hainan & 0.3810 & 0.3171 \\
\hline Hami Area & Xinjiang & 0.3816 & 0.5044 \\
\hline Jieyang City & Guangdong & 0.3819 & 0.4081 \\
\hline Xiaogan City & Hubei & 0.3837 & 0.3904 \\
\hline Dalian City & Liaoning & 0.3859 & 0.4614 \\
\hline Zhangzhou City & Fujian & 0.3870 & 0.3723 \\
\hline Jinzhong City & Shanxi & 0.3872 & 0.3969 \\
\hline Xuzhou City & Jiangsu & 0.3874 & 0.4959 \\
\hline Guiyang City & Guizhou & 0.3879 & 0.4405 \\
\hline Kaifeng City & Henan & 0.3907 & 0.3581 \\
\hline Foshan City & Guangdong & 0.3915 & 0.2867 \\
\hline Zhengzhou City & Henan & 0.3942 & 0.2837 \\
\hline Baoji City & Shaanxi & 0.3942 & 0.3560 \\
\hline Wenzhou City & Fujian & 0.3965 & 0.4286 \\
\hline Yangzhou City & Jiangsu & 0.3976 & 0.3826 \\
\hline Huhehaote City & Inner Mongolia & 0.3978 & 0.4516 \\
\hline Tongchuan City & Shaanxi & 0.3992 & 0.4539 \\
\hline Anshan City & Liaoning & 0.4015 & 0.3501 \\
\hline Rizhao City & Shandong & 0.4024 & 0.3711 \\
\hline
\end{tabular}


Table A1. Cont.

\begin{tabular}{|c|c|c|c|}
\hline Prefectural City & Province & NLDI2005 & NLDI2010 \\
\hline Wuhan City & Hubei & 0.4024 & 0.3511 \\
\hline Suqian City & Jiangsu & 0.4058 & 0.3775 \\
\hline Shenzhen City & Guangdong & 0.4061 & 0.2684 \\
\hline Chaozhou City & Guangdong & 0.4062 & 0.4119 \\
\hline Nanchang City & Jiangxi & 0.4063 & 0.3765 \\
\hline Lanzhou City & Gansu & 0.4076 & 0.4328 \\
\hline Yangquan City & Shanxi & 0.4091 & 0.4486 \\
\hline Suihua City & Heilongjiang & 0.4091 & 0.4108 \\
\hline Dandong City & Liaoning & 0.4108 & 0.5060 \\
\hline Wenzhou City & Zhejiang & 0.4137 & 0.3942 \\
\hline Qitaihe City & Heilongjiang & 0.4143 & 0.4648 \\
\hline Chaoyang City & Liaoning & 0.4144 & 0.4607 \\
\hline Puyang City & Henan & 0.4163 & 0.2677 \\
\hline Jingzhou City & Hubei & 0.4186 & 0.4027 \\
\hline Zhongshan City & Guangdong & 0.4211 & 0.2874 \\
\hline Deyang City & Sichuan & 0.4216 & 0.4158 \\
\hline Taizhou City & Jiangsu & 0.4243 & 0.4569 \\
\hline Shuozhou City & Shanxi & 0.4286 & 0.4449 \\
\hline Dongying City & Shandong & 0.4288 & 0.3553 \\
\hline Huangshi City & Hubei & 0.4289 & 0.3465 \\
\hline Baoting County & Hainan & 0.4290 & 0.4251 \\
\hline Huludao City & Liaoning & 0.4292 & 0.4694 \\
\hline Jixi City & Heilongjiang & 0.4331 & 0.4561 \\
\hline Nantong City & Jiangsu & 0.4343 & 0.4620 \\
\hline Bo'ertala Autonomous Prefecture & Xinjiang & 0.4352 & 0.4296 \\
\hline Kelamayi City & Xinjiang & 0.4412 & 0.3844 \\
\hline Jiamusi City & Heilongjiang & 0.4421 & 0.5360 \\
\hline Xinzhou City & Shanxi & 0.4426 & 0.4413 \\
\hline Baotou City & Inner Mongolia & 0.4448 & 0.5317 \\
\hline Chenzhou City & Hunan & 0.4452 & 0.4917 \\
\hline Mudanjiang City & Heilongjiang & 0.4455 & 0.4848 \\
\hline Sanya City & Hainan & 0.4507 & 0.3051 \\
\hline Tunchang County & Hainan & 0.4513 & 0.3039 \\
\hline Ledong County & Hainan & 0.4520 & 0.3939 \\
\hline Yancheng City & Jiangsu & 0.4526 & 0.4531 \\
\hline Changzhi City & Shanxi & 0.4526 & 0.3848 \\
\hline Hefei City & Anhui & 0.4534 & 0.4001 \\
\hline Ningde City & Fujian & 0.4542 & 0.4886 \\
\hline Longyan City & Fujian & 0.4557 & 0.5416 \\
\hline Haikou City & Hainan & 0.4565 & 0.2833 \\
\hline Kezilesuke'erkezi Autonomous Prefecture & Xinjiang & 0.4599 & 0.5100 \\
\hline Zhuzhou City & Hunan & 0.4619 & 0.5062 \\
\hline Nanyang City & Henan & 0.4632 & 0.3494 \\
\hline Datong City & Shanxi & 0.4645 & 0.4074 \\
\hline Qinhuangdao City & Hebei & 0.4682 & 0.4144 \\
\hline
\end{tabular}


Table A1. Cont.

\begin{tabular}{|c|c|c|c|}
\hline Prefectural City & Province & NLDI2005 & NLDI2010 \\
\hline Bozhou City & Anhui & 0.4687 & 0.4128 \\
\hline Fuxin City & Anhui & 0.4706 & 0.3957 \\
\hline Siping City & Jilin & 0.4708 & 0.4402 \\
\hline Zhumadian City & Henan & 0.4726 & 0.3962 \\
\hline Maanshan City & Anhui & 0.4741 & 0.3683 \\
\hline Hengyang City & Hunan & 0.4797 & 0.5201 \\
\hline Ha'erbin City & Heilongjiang & 0.4798 & 0.4239 \\
\hline Panzhihua City & Sichuan & 0.4822 & 0.3600 \\
\hline Suizhou City & Hubei & 0.4843 & 0.5640 \\
\hline Danzhou City & Hainan & 0.4844 & 0.3926 \\
\hline Xianyang City & Shaanxi & 0.4895 & 0.4091 \\
\hline Yichang City & Hubei & 0.4896 & 0.4910 \\
\hline Ding'an County & Hainan & 0.4920 & 0.5511 \\
\hline Anshun City & Guizhou & 0.4938 & 0.4960 \\
\hline Wenchang City & Hainan & 0.4953 & 0.4317 \\
\hline Shizuishan City & Ningxia & 0.4959 & 0.4537 \\
\hline Zhangjiakou City & Hebei & 0.4987 & 0.5158 \\
\hline Wuzhong City & Ningxia & 0.5029 & 0.5830 \\
\hline Linfen City & Shanxi & 0.5036 & 0.3662 \\
\hline Qiqiha'er City & Heilongjiang & 0.5045 & 0.5095 \\
\hline Zhangjiajie City & Hunan & 0.5054 & 0.6257 \\
\hline Loudi City & Hunan & 0.5087 & 0.4735 \\
\hline Yingtan City & Jiangxi & 0.5089 & 0.5391 \\
\hline Chuzhou City & Anhui & 0.5111 & 0.4282 \\
\hline Yueyang City & Hunan & 0.5116 & 0.4855 \\
\hline Bengbu City & Anhui & 0.5122 & 0.4813 \\
\hline Guangzhou City & Guangdong & 0.5125 & 0.4152 \\
\hline Yichun City & Heilongjiang & 0.5126 & 0.5218 \\
\hline Yuxi Area & Yunnan & 0.5136 & 0.4943 \\
\hline Yongzhou City & Hunan & 0.5159 & 0.5414 \\
\hline Zhanjiang City & Guangdong & 0.5167 & 0.4431 \\
\hline Lishui City & Zhejiang & 0.5174 & 0.5472 \\
\hline Jingmen City & Hubei & 0.5183 & 0.5223 \\
\hline Maoming City & Guangdong & 0.5185 & 0.5104 \\
\hline Changde City & Hunan & 0.5192 & 0.5071 \\
\hline Huaihua City & Hunan & 0.5218 & 0.5869 \\
\hline Suzhou City & Anhui & 0.5231 & 0.3689 \\
\hline Jiangmen City & Guangdong & 0.5233 & 0.4115 \\
\hline Bayannaoer League & Inner Mongolia & 0.5270 & 0.4277 \\
\hline Kunming City & Yunnan & 0.5279 & 0.4816 \\
\hline Heihe City & Heilongjiang & 0.5281 & 0.5378 \\
\hline Neijiang City & Sichuan & 0.5297 & 0.4966 \\
\hline Zhuhai City & Guangdong & 0.5302 & 0.5229 \\
\hline Lvliang Area & Shanxi & 0.5323 & 0.4662 \\
\hline Xinyu City & Jiangxi & 0.5355 & 0.5220 \\
\hline
\end{tabular}


Table A1. Cont.

\begin{tabular}{|c|c|c|c|}
\hline Prefectural City & Province & NLDI2005 & NLDI2010 \\
\hline Chaohu City & Anhui & 0.5363 & 0.4613 \\
\hline Anqing City & Anhui & 0.5367 & 0.4534 \\
\hline Yangjiang City & Guangdong & 0.5401 & 0.4890 \\
\hline Huizhou City & Guangdong & 0.5412 & 0.4439 \\
\hline Yiyang City & Hunan & 0.5452 & 0.5623 \\
\hline Qujing City & Yunnan & 0.5466 & 0.5382 \\
\hline Baisha County & Hainan & 0.5470 & 0.3092 \\
\hline Daqing City & Heilongjiang & 0.5490 & 0.5380 \\
\hline Changji Autonomous Prefecture & Xinjiang & 0.5497 & 0.4867 \\
\hline Xiangfan City & Hubei & 0.5504 & 0.5090 \\
\hline Meizhou City & Guangdong & 0.5517 & 0.4652 \\
\hline Leshan City & Sichuan & 0.5523 & 0.5388 \\
\hline Wuhu City & Anhui & 0.5559 & 0.3541 \\
\hline Shiyan City & Hubei & 0.5582 & 0.5302 \\
\hline Enshi Autonomous Prefecture & Hubei & 0.5587 & 0.4624 \\
\hline Linxia Autonomous Prefecture & Gansu & 0.5593 & 0.4226 \\
\hline Yichun City & Jiangxi & 0.5595 & 0.5324 \\
\hline Lasa City & Xizang & 0.5622 & 0.5703 \\
\hline Huanggang City & Hubei & 0.5650 & 0.4297 \\
\hline Shaoyang City & Hunan & 0.5652 & 0.5763 \\
\hline Xianning City & Hubei & 0.5669 & 0.5235 \\
\hline Guigang City & Guangxi & 0.5678 & 0.4829 \\
\hline Tonghua City & Jilin & 0.5707 & 0.4540 \\
\hline Chengmai County & Hainan & 0.5751 & 0.5190 \\
\hline Shaoguan City & Guangdong & 0.5764 & 0.5525 \\
\hline Qiongzhong County & Hainan & 0.5777 & 0.5398 \\
\hline Qingyuan City & Guangdong & 0.5787 & 0.5553 \\
\hline Hulunbei'er City & Inner Mongolia & 0.5788 & 0.6161 \\
\hline Shantou City & Guangdong & 0.5788 & 0.5098 \\
\hline Meishan City & Sichuan & 0.5802 & 0.4899 \\
\hline Yili Autonomous Prefecture & Xinjiang & 0.5896 & 0.5347 \\
\hline Jingdezhen City & Jiangxi & 0.5902 & 0.4734 \\
\hline Huangnan Autonomous Prefecture & Qinghai & 0.5911 & 0.5179 \\
\hline Yulin City & Guangxi & 0.5918 & 0.4278 \\
\hline Zhaoqing City & Guangdong & 0.5944 & 0.5467 \\
\hline Ya'an City & Sichuan & 0.5958 & 0.6188 \\
\hline Xinyang City & Henan & 0.6014 & 0.5833 \\
\hline Tongliao City & Inner Mongolia & 0.6025 & 0.6029 \\
\hline Hanzhong City & Shaanxi & 0.6032 & 0.5665 \\
\hline Sanming City & Fujian & 0.6046 & 0.6091 \\
\hline Yanbian Autonomous Prefecture & Jilin & 0.6049 & 0.4400 \\
\hline Guyuan City & Ningxia & 0.6072 & 0.5863 \\
\hline Xishuangbanna Autonomous Prefecture & Yunnan & 0.6102 & 0.6191 \\
\hline Guangan City & Sichuan & 0.6121 & 0.6529 \\
\hline Liupanshui City & Guizhou & 0.6129 & 0.5681 \\
\hline
\end{tabular}


Table A1. Cont.

\begin{tabular}{|c|c|c|c|}
\hline Prefectural City & Province & NLDI2005 & NLDI2010 \\
\hline Honhhe Autonomous Prefecture & Yunnan & 0.6132 & 0.5939 \\
\hline Tongshi City & Hainan & 0.6138 & 0.4251 \\
\hline Chengde City & Hebei & 0.6146 & 0.6001 \\
\hline E'erduosi City & Inner Mongolia & 0.6198 & 0.6319 \\
\hline Liuzhou City & Guangxi & 0.6204 & 0.5283 \\
\hline Qianxinan Autonomous Prefecture & Guizhou & 0.6233 & 0.5972 \\
\hline Chizhou City & Anhui & 0.6236 & 0.5516 \\
\hline Chongqing City & Chongqing & 0.6248 & 0.6434 \\
\hline Shangrao City & Jiangxi & 0.6284 & 0.5557 \\
\hline Shangluo City & Shaanxi & 0.6287 & 0.6328 \\
\hline Haidong Area & Qinghai & 0.6316 & 0.5469 \\
\hline Aletai Area & Xinjiang & 0.6340 & 0.5874 \\
\hline Dali Autonomous Prefecture & Yunnan & 0.6355 & 0.5109 \\
\hline Xuancheng City & Anhui & 0.6363 & 0.4727 \\
\hline Huangshan City & Anhui & 0.6378 & 0.4996 \\
\hline Hezhou City & Guangxi & 0.6380 & 0.6052 \\
\hline Fuzhou City & Jiangxi & 0.6399 & 0.5919 \\
\hline Xiangxi Autonomous Prefecture & Hunan & 0.6400 & 0.7045 \\
\hline Yunfu City & Guangdong & 0.6426 & 0.5410 \\
\hline Daxing'anling Area & Heilongjiang & 0.6427 & 0.6916 \\
\hline Dehong Autonomous Prefecture & Yunnan & 0.6469 & 0.4674 \\
\hline Baishan City & Jilin & 0.6514 & 0.6348 \\
\hline Jilin City & Jilin & 0.6533 & 0.4464 \\
\hline Ganzhou City & Jiangxi & 0.6570 & 0.6306 \\
\hline Suining City & Sichuan & 0.6573 & 0.6077 \\
\hline Mianyang City & Sichuan & 0.6582 & 0.5722 \\
\hline Songyuan City & Jilin & 0.6594 & 0.4761 \\
\hline Fangchenggang City & Guangxi & 0.6600 & 0.5105 \\
\hline Baoshan City & Yunnan & 0.6641 & 0.4672 \\
\hline Bayinguoleng Autonomous Prefecture & Xinjiang & 0.6649 & 0.5387 \\
\hline Lu'an Area & Anhui & 0.6653 & 0.6058 \\
\hline Zigong City & Sichuan & 0.6667 & 0.5875 \\
\hline Wulanchabu League & Inner Mongolia & 0.6725 & 0.6870 \\
\hline Alashan League & Inner Mongolia & 0.6748 & 0.6006 \\
\hline Heyuan City & Guangdong & 0.6769 & 0.6463 \\
\hline Wuzhou City & Guangxi & 0.6773 & 0.5340 \\
\hline Guoluo Autonomous Prefecture & Qinghai & 0.6775 & 0.4940 \\
\hline Changchun City & Jilin & 0.6794 & 0.3849 \\
\hline Jiujiang City & Jiangxi & 0.6829 & 0.6161 \\
\hline Nanping City & Fujian & 0.6842 & 0.6679 \\
\hline Chongzuo City & Guangxi & 0.6857 & 0.5528 \\
\hline Qiannan Autonomous Prefecture & Guizhou & 0.6879 & 0.6971 \\
\hline Xing'an League & Inner Mongolia & 0.6906 & 0.6015 \\
\hline Tulufan City & Xinjiang & 0.6943 & 0.6139 \\
\hline Tacheng Area & Xinjiang & 0.6977 & 0.5936 \\
\hline
\end{tabular}


Table A1. Cont.

\begin{tabular}{|c|c|c|c|}
\hline Prefectural City & Province & NLDI2005 & NLDI2010 \\
\hline Guilin City & Guangxi & 0.6979 & 0.5536 \\
\hline Hetian Area & Xinjiang & 0.7001 & 0.5138 \\
\hline Jinchang City & Gansu & 0.7004 & 0.5537 \\
\hline Xilinguole League & Inner Mongolia & 0.7110 & 0.7365 \\
\hline Haixi Autonomous Prefecture & Qinghai & 0.7129 & 0.6887 \\
\hline Zunyi City & Guizhou & 0.7157 & 0.7018 \\
\hline Chifeng City & Inner Mongolia & 0.7164 & 0.6157 \\
\hline Luzhou City & Sichuan & 0.7195 & 0.6763 \\
\hline Yibin City & Sichuan & 0.7201 & 0.6893 \\
\hline Yan'an City & Shaanxi & 0.7213 & 0.7150 \\
\hline Ankang City & Shaanxi & 0.7215 & 0.6330 \\
\hline Qinzhou City & Guangxi & 0.7244 & 0.6168 \\
\hline Dazhou City & Sichuan & 0.7255 & 0.7617 \\
\hline Ji'an City & Jiangxi & 0.7261 & 0.7555 \\
\hline Bijie Area & Guizhou & 0.7373 & 0.6872 \\
\hline Tongren Area & Guizhou & 0.7383 & 0.7620 \\
\hline Wuwei City & Gansu & 0.7434 & 0.5246 \\
\hline Tianshui City & Gansu & 0.7467 & 0.4599 \\
\hline Laibin City & Guangxi & 0.7474 & 0.7774 \\
\hline Chuxiong Autonomous Prefecture & Yunnan & 0.7493 & 0.6666 \\
\hline Kashi Area & Xinjiang & 0.7502 & 0.5330 \\
\hline Akesu Area & Xinjiang & 0.7516 & 0.7050 \\
\hline Qiandong Autonomous Prefecture & Guizhou & 0.7590 & 0.7480 \\
\hline Liangshan Autonomous Prefecture & Sichuan & 0.7666 & 0.7053 \\
\hline Yulin City & Shaanxi & 0.7687 & 0.7471 \\
\hline Nanchong City & Sichuan & 0.7689 & 0.7490 \\
\hline Lincang & Yunnan & 0.7852 & 0.6714 \\
\hline Nanning City & Guangxi & 0.7868 & 0.5697 \\
\hline Baiyin City & Gansu & 0.7886 & 0.6710 \\
\hline Qingyang City & Gansu & 0.7909 & 0.6750 \\
\hline Haibei Autonomous Prefecture & Qinghai & 0.7911 & 0.7233 \\
\hline Baicheng City & Jilin & 0.7925 & 0.5639 \\
\hline Diqing Autonomous Prefecture & Yunnan & 0.7926 & 0.7251 \\
\hline Naqu Area & Xizang & 0.7940 & 0.7673 \\
\hline Ziyang City & Sichuan & 0.7967 & 0.7536 \\
\hline Linzhi Area & Xizang & 0.8080 & 0.7951 \\
\hline Lijiang Area & Yunnan & 0.8082 & 0.6601 \\
\hline Wenshan Autonomous Prefecture & Yunnan & 0.8087 & 0.7963 \\
\hline Zhaotong City & Yunnan & 0.8089 & 0.8142 \\
\hline Bose City & Guangxi & 0.8094 & 0.7153 \\
\hline Simao Area & Yunnan & 0.8128 & 0.8005 \\
\hline Guangyuan City & Sichuan & 0.8137 & 0.7710 \\
\hline Ganzi Autonomous Prefecture & Sichuan & 0.8142 & 0.8402 \\
\hline Ali Area & Xizang & 0.8212 & 0.7963 \\
\hline Longnan City & Gansu & 0.8235 & 0.6177 \\
\hline
\end{tabular}


Table A1. Cont.

\begin{tabular}{cccc}
\hline Prefectural City & Province & NLDI2005 & NLDI2010 \\
\hline Pingliang City & Gansu & 0.8265 & 0.5124 \\
Nujiang Autonomous Prefecture & Yunnan & 0.8339 & 0.6910 \\
Gannan Autonomous Prefecture & Gansu & 0.8355 & 0.6051 \\
Aba Autonomous Prefecture & Sichuan & 0.8374 & 0.7806 \\
Yushu Autonomous Prefecture & Qinghai & 0.8390 & 0.8041 \\
Hechi City & Guangxi & 0.8401 & 0.7748 \\
Dingxi Area & Gansu & 0.8446 & 0.5502 \\
Jiuquan City & Gansu & 0.8691 & 0.6475 \\
Shannan Area & Xizang & 0.8807 & 0.8468 \\
Rikaze Area & Xizang & 0.8937 & 0.8506 \\
Hainan Autonomous Prefecture & Qinghai & 0.9021 & 0.7499 \\
Bazhong City & Sichuan & 0.9050 & 0.8715 \\
Changdu Area & Xizang & 0.9123 & 0.8830 \\
Zhangye City & Gansu & 0.9456 & 0.5806 \\
\hline
\end{tabular}

\section{References}

1. Lo, T.W.; Jiang, G. Inequality, crime and the floating population in China. Asian J. Criminol. 2006, $1,103-118$.

2. Wei, Y.D. Regional Development in China: States, Globalization and Inequality; Routledge: London, UK, 2013.

3. Zhang, Z.; Yao, S. Regional inequalities in contemporary China measured by GDP and consumption. Econ. Issues-Stoke Trent 2001, 6, 13-30.

4. Chan, K.W.; Wang, M. Remapping China's Regional Inequalities, 1990-2006: A New Assessment of De Facto and De Jure Population Data. Eurasian Geogr. Econ. 2008, 49, 21-56.

5. Yu, D.L.; Wei, Y.H.D. Spatial data analysis of regional development in greater Beijing, China, in a GIS environment. Paper. Reg. Sci. 2008, 87, 97-117.

6. Liu, T.; Li, K.W. Disparity in factor contributions between coastal and inner provinces in post-reform China. China Econ. Rev. 2006, 17, 449-470.

7. Demurger, S. Infrastructure development and economic growth: An explanation for regional disparities in China? J. Comp. Econ. 2001, 29, 95-117.

8. Kanbur, R.; Zhang, X. Fifty years of regional inequality in China: A journey through central planning, reform, and openness. Rev. Dev. Econ. 2005, 9, 87-106.

9. Measurement of GDP Per Capita and Regional Disparities in China, 1979-2009. Available online: http:/ggl.rieb.kobe-u.ac.jp/academic/ra/dp/English/DP2011-17.pdf (accessed on 16 September 2015).

10. Li, Y.; Wei, Y.D. The spatial-temporal hierarchy of regional inequality of China. Appl. Geogr. 2010, 30, 303-316.

11. Li, C.; Gibson, J.R. Regional inequality in China: Fact or artifact? World Dev. 2013, 47, 16-29.

12. Rigall-I-Torrent, R. Sustainable development in tourism municipalities: The role of public goods. Tour. Manag. 2008, 29, 883-897. 
13. Liu, Y.X.; Wei, L.S.; Qiu, M.J., Status and problem analysis on public service supply in Pastoral Areas of inner mongolia-based on perspective of sustainable development. In Proceedings of 2013 International Conference on Public Administration, Cape Town, South Africa, 31 October 2013; Zhu, X.N., Zhao, S.R., Eds.; University of Electronic Science and Technology of China Press: Chengdu, China, 2013; pp. 530-536.

14. Liang, X.P. Functions of public service in the sustainable development of regional economy: A case study of Tianjin. Appl. Mech. Mater. 2014, 472, 1105-1111.

15. Argyriades, D. Values for public service: Lessons learned from recent trends and the millennium summit. Int. Rev. Adm. Sci. 2003, 69, 521-533.

16. Zhang, X.; Kanbur, R. Spatial inequality in education and health care in China. China Econ. Rev. 2005, 16, 189-204.

17. Li, Y.; Wei, Y.D. Multidimensional inequalities in health care distribution in provincial China: A case study of Henan Province. Tijdschr. Voor Econo. En Soc. Geogr. 2014, 105, 91-106.

18. Feng, X.L.; Zhu, J.; Zhang, L.; Song, L.; Hipgrave, D.; Guo, S.; Ronsmans, C.; Guo, Y.; Yang, Q. Socio-economic disparities in maternal mortality in China between 1996 and 2006. Bjog-An Int. J. Obstet. Gynaecol. 2010, 117, 1527-1536.

19. Chou, W.L.; Wang, Z.J. Regional inequality in China's health care expenditures. Health Econ. 2009, 18, S137-S146.

20. Fan, C.C.; Sun, M. Regional inequality in China, 1978-2006. Eurasian Geogr. Econ. 2008, 49, 1-18.

21. Liao, F.H.; Wei, Y.D. Dynamics, space, and regional inequality in provincial china: A case study of Guangdong province. Appl. Geogr. 2012, 35, 71-83.

22. Yue, W.; Zhang, Y.; Ye, X.; Cheng, Y.; Leipnik, M.R. Dynamics of Multi-scale Intra-provincial Regional Inequality in Zhejiang, China. Sustainability 2014, 6, 5763-5784.

23. Margono, B.A.; Bwangoy, J.R.B.; Potapov, P.V.; Hansen, M.C. Mapping Wetlands in Indonesia using Landsat and PALSAR Data-Sets and Derived Topographical Indices. Geo-Spat. Inf. Sci. 2014, 17, 60-71.

24. Xu, Y.; Huang, B. Spatial and Temporal Classification of Synthetic Satellite Imagery: Land Cover Mapping and Accuracy Validation. Geo-Spat. Inf. Sci. 2014, 17, 1-7.

25. Hansen, M.C.; Loveland, T.R. A Review of Large Area Monitoring of Land Cover Change Using Landsat Data. Remote Sens. Environ. 2012, 122, 66-74.

26. Zhai, K.; Wu, X.; Qin, Y.; Du, P. Comparison of Surface Water Extraction Performances of Different Classic Water Indices using OLI and TM Imageries in Different Situations. Geo-Spat. Inf. Sci. 2015, 18, 32-42.

27. Du, P.; Liu, S.; Liu, P.; Tan, K.; Cheng, L. Sub-pixel Change Detection for Urban Land-cover Analysis via Multi-temporal Remote Sensing Images. Geo-Spat. Inf. Sci. 2014, 17, 26-38.

28. Friedl, M.A.; Brodley, C.E. Decision Tree Classification of Land Cover from Remotely Sensed Data. Remote Sens. Environ. 1997, 61, 399-409.

29. Jiang, B.; Bamutaze, Y.; Pilesjö, P. Climate Change and Land Degradation in Africa: A Case Study in the Mount Elgon Region, Uganda. Geo-Spat. Inf. Sci. 2014, 17, 39-53.

30. Brown, M.; De Beurs, K.; Marshall, M. Global Phenological Response to Climate Change in Crop Areas Using Satellite Remote Sensing of Vegetation, Humidity and Temperature Over 26years. Remote Sens. Environ. 2012, 126, 174-183. 
31. Bello, O.M.; Aina, Y.A. Satellite Remote Sensing as A Tool in Disaster Management and Sustainable Development: Towards A Synergistic Approach. Proced.-Soc. Behav. Sci. 2014, 120, 365-373.

32. Elvidge, C.D.; Baugh, K.E.; Kihn, E.A.; Kroehl, H.W.; Davis, E.R.; Davis, C.W. Relation Between Satellite Observed Visible-near Infrared Emissions, Population, Economic Activity and Electric Power Consumption. Int. J. Remote Sens. 1997, 18, 1373-1379.

33. Ghosh, T.; Powell, R.L.; Elvidge, C.D.; Baugh, K.E.; Sutton, P.C.; Anderson, S. Shedding Light on the Global Distribution of Economic Activity. Open Geogr. J. 2010, 3, 148-161.

34. Henderson, J.V.; Storeygard, A.; Weil, D.N. Measuring Economic Growth from Outer Space. Am. Econ. Rev. 2012, 102, 994-1028.

35. Amaral, S.; Câmara, G.; Monteiro, A.M.V.; Quintanilha, J.A.; Elvidge, C.D. Estimating Population and Energy Consumption in Brazilian Amazonia using DMSP Night-time Satellite Data. Computers, Environ. Urban Syst. 2005, 29, 179-195.

36. Li, X.; Xu, H.; Chen, X.; Li, C. Potential of NPP-VIIRS Nighttime Light Imagery for Modeling the Regional Economy of China. Remote Sens. 2013, 5, 3057-3081.

37. Gibson, J.; Li, C.; Boe-Gibson, G. Economic Growth and Expansion of China's Urban Land Area: Evidence from Administrative Data and Night Lights, 1993-2012. Sustainability 2014, 6, 7850-7865.

38. Liu, Z.F.; He, C.Y.; Zhang, Q.F.; Huang, Q.X.; Yang, Y. Extracting the Dynamics of Urban Expansion in China using DMSP-OLS Nighttime Light Data from 1992 to 2008. Lands. Urban Plan. 2012, 106, 62-72.

39. Waluda, C.M.; Griffiths, H.J.; Rodhouse, P.G. Remotely Sensed Spatial Dynamics of the Illex Argentinus Fishery, Southwest Atlantic. Fish. Res. 2008, 91, 196-202.

40. Shi, K.; Yu, B.; Huang, Y.; Hu, Y.; Yin, B.; Chen, Z.; Chen, L.; Wu, J. Evaluating the Ability of NPP-VIIRS Nighttime Light Data to Estimate the Gross Domestic Product and the Electric Power Consumption of China at Multiple Scales: A Comparison with DMSP-OLS Data. Remote Sens. 2014, 6, 1705-1724.

41. Shi, K.; Huang, C.; Yu, B.; Yin, B.; Huang, Y.; Wu, J. Evaluation of NPP-VIIRS Night-time Light Composite Data for Extracting Built-up Urban Areas. Remote Sens. Lett. 2014, 5, 358-366.

42. Huang, Q.; He, C.; Gao, B.; Yang, Y.; Liu, Z.; Zhao, Y.; Dou, Y. Detecting the 20 Year City-size Dynamics in China with a Rank Clock Approach and DMSP/OLS Nighttime Data. Lands. Urban Plan. 2015, 137, 138-148.

43. Zhou, Y.; Smith, S.J.; Elvidge, C.D.; Zhao, K.; Thomson, A.; Imhoff, M. A Cluster-based Method to Map Urban Area from DMSP/OLS nightlights. Remote Sens. Environ. 2014, 147, 173-185.

44. Li, X.; Zhang, R.; Huang, C.; Li, D. Detecting 2014 Northern Iraq Insurgency Using Night-Time Light Imagery. Int. J. Remote Sens. 2015, 36, 3446-3458.

45. Li, X.; Li, D. Can Night-time Light Images Play a Role in Evaluating the Syrian Crisis? Int. J. Remote Sens. 2014, 35, 6648-6661.

46. Li, X.; Ge, L.; Chen, X. Detecting Zimbabwe's Decadal Economic Decline Using Nighttime Light Imagery. Remote Sens. 2013, 5, 4551-4570.

47. Doll, C.N.H.; Muller, J.P.; Morley, J.G. Mapping Regional Economic Activity from Night-time Light Satellite Imagery. Ecol. Econ. 2006, 57, 75-92. 
48. Chen, X.; Nordhaus, W.D. Using Luminosity Data as a Proxy for Economic Statistics. Proc. Natl. Acad. Sci. 2011, 108, 8589-8594.

49. Doll, C.N.H.; Muller, J.P.; Elvidge, C.D. Night-time Imagery as a Tool for Global Mapping of Socioeconomic Parameters and Greenhouse Gas Emissions. Ambio 2000, 29, 157-162.

50. He, C.; Ma, Q.; Liu, Z.; Zhang, Q. Modeling the Spatiotemporal Dynamics of Electric Power Consumption in Mainland China Using Saturation-corrected DMSP/OLS Nighttime Stable Light Data. Inter. J. Digit. Earth 2013, 7, 1-22.

51. Min, B. Democracy and Light: Electoral Accountability and the Provision of Public Goods. In Proceedings of Annual Meeting of the Midwest Political Science Association, Chicago, IL, USA, 3 April 2008.

52. Better Life For All? Democratization and Electrification in Post-Apartheid South Africa. Available online: http://personal.lse.ac.uk/LARCINES/electrification\%202014\%20working\%20paper.pdf (accessed on 16 September 2015).

53. Yang, Y.; He, C.Y.; Zhang, Q.F.; Han, L.J.; Du, S.Q. Timely and Accurate National-scale Mapping of Urban Land in China Using Defense Meteorological Satellite Program's Operational Linescan System Nighttime Stable Light Data. J. Appl. Remote Sens. 2013, 7, 1-35.

54. Yi, K.; Tani, H.; Li, Q.; Zhang, J.; Guo, M.; Bao, Y.; Wang, X.; Li, J. Mapping and Evaluating the Urbanization Process in Northeast China Using DMSP/OLS Nighttime Light Data. Sensors 2014, 14, 3207-3226.

55. Tan, M. Urban Growth and Rural Transition in China Based on DMSP/OLS Nighttime Light Data. Sustainability 2015, 7, 8768-8781.

56. Elvidge, C.; Baugh, K.; Anderson, S.; Sutton, P.; Ghosh, T. The Night Light Development Index (NLDI): A Spatially Explicit Measure of Human Development from Satellite Data. Soc. Geogr. 2012, 7, 23-35.

57. Zhou, Y.K.; Ma, T.; Zhou, C.H.; Xu, T. Nighttime Light Derived Assessment of Regional Inequality of Socioeconomic Development in China. Remote Sens. 2015, 7, 1242-1262.

58. Liu, J.; Li, W. A Nighttime Light Imagery Estimation of Ethnic Disparity in Economic Well-being in Mainland China and Taiwan (2001-2013). Eurasian Geogr. Econ. 2014, 55, 691-714.

59. Kuechly, H.U.; Kyba, C.C.M.; Ruhtz, T.; Lindemann, C.; Wolter, C.; Fischer, J.; Holker, F. Aerial Survey and Spatial Analysis of Sources of Light Pollution in Berlin, Germany. Remote Sens. Environ. 2012, 126, 39-50.

60. Keola, S.; Andersson, M.; Hall, O. Monitoring Economic Development from Space: Using Nighttime Light and Land Cover Data to Measure Economic Growth. World Dev. 2015, 66, 322-334.

61. Wang, M. Key Issues in China's Development; China Development Press: Beijing, China, 2005.

62. $1 \mathrm{KM}$ Grid Population Dataset of China. Available online: http://www.geodoi.ac.cn/ WebEn/doi.aspx?Id=131 (accessed on 16 September 2015).

63. Global Radiance Calibrated Nighttime Lights. Available online: http://ngdc.noaa.gov/eog/dmsp/ download_radcal.html (accessed on 16 September 2015)

64. Ma, L.; Wu, J.S.; Li, W.F.; Peng, J.; Liu, H. Evaluating Saturation Correction Methods for DMSP/OLS Nighttime Light Data: A Case Study from China's Cities. Remote Sens. 2014, 6, 9853-9872.

65. Letu, H.; Hara, M.; Tana, G.; Nishio, F. A Saturated Light Correction Method for DMSP/OLS Nighttime Satellite Imagery. IEEE Trans. Geosci. Remote Sens. 2012, 50, 389-396. 
66. National Geophysical Data Center. Version 4 DMSP-OLS Nighttime Lights Time Series. Available online: http://ngdc.noaa.gov/eog/dmsp/downloadV4composites.html (accessed on 16 September 2015)

67. Tuttle, B.T.; Anderson, S.J.; Sutton, P.C.; Elvidge, C.D.; Baugh, K. It Used To Be Dark Here. Photogramm. Eng. Remote Sens. 2013, 79, 287-297.

68. Wan, G. Understanding Regional Poverty and Inequality Trends in China: Methodological Issues and Empirical Findings. Rev. Income Wealth 2007, 53, 25-34.

69. Ye, J.; James, M.; Wang, Y. Left-Behind Children in Rural China; Paths International Limited: Reading, UK, 2011.

(C) 2015 by the authors; licensee MDPI, Basel, Switzerland. This article is an open access article distributed under the terms and conditions of the Creative Commons Attribution license (http://creativecommons.org/licenses/by/4.0/). 